UNIVERSIDADE DE SÃO PAULO

FACULDADE DE MEDICINA DE RIBEIRÃO PRETO

DEPARTAMENTO DE BIOQUÍMICA E IMUNOLOGIA

PÓS-GRADUAÇÃO EM IMUNOLOGIA BÁSICA E APLICADA

\title{
Alarmina S100A9: um mediador crítico no desenvolvimento da psoríase
}

Bruno Marcel Silva de Melo

Dissertação apresentada ao Programa de PósGraduação em Imunologia Básica e Aplicada da Faculdade de Medicina de Ribeirão Preto da Universidade de São Paulo, para a obtenção do título de Mestre em Ciências. Área de Concentração: Imunologia Básica e Aplicada.

Orientador: Prof. Dr. José Carlos Farias Alves Filho

Ribeirão Preto 
Autorizo a reprodução e divulgação total ou parcial deste trabalho, por qualquer meio convencional ou eletrônico, para fins de estudo e pesquisa, desde que citada a fonte.

\section{FICHA CATALOGRÁFICA}

Melo, Bruno Marcel Silva de

Alarmina S100A9: um mediador crítico no desenvolvimento da psoríase. Ribeirão Preto, 2017

$77 p$.

Dissertação de Mestrado, apresentada ao Programa de PósGraduação em Imunologia Básica e Aplicada da Faculdade de Medicina de Ribeirão Preto da Universidade de São Paulo para obtenção do título de Mestre em Ciências. Área de concentração: Imunologia Básica e Aplicada

Orientador: Alves-Filho, José Carlos Farias

1. Psoríase. 2. S100A9. 3. Imunopatogênse. 
Nome: Bruno Marcel Silva de Melo

Título: Alarmina S100A9: um mediador crítico no desenvolvimento da psoríase

Dissertação apresentada ao Programa de PósGraduação em Imunologia Básica e Aplicada da Faculdade de Medicina de Ribeirão Preto da Universidade de São Paulo, para a obtenção do título de Mestre em Ciências. Área de Concentração: Imunologia Básica e Aplicada

Aprovado em:

\section{Banca Examinadora}

Prof. Dr. José Carlos Farias Alves Filho. Instituição: Faculdade de Medicina de Ribeirão Preto Julgamento: Assinatura

Profa. Dr. Paulo Louzada Junior. Instituição: Faculdade de Medicina de Ribeirão Preto Julgamento: Assinatura

Prof.Dra. Alexandra Ivo de Medeiros. Instituição: Faculdade de Ciências Farmacêuticas, UNESP Araraquara

Julgamento: Assinatura

Profa. Dr. Flávio Almeida Amaral. Instituição: Instituto de Ciências Biológicas da Universidade Federal de Minas Gerais Julgamento: Assinatura 
"Nada deve parecer impossível de mudar" Bertolt Brecht 
Dedico este trabalho à minha família, em especial à minha avó, Maria Lêda, que fez de tudo para tornar real os sonhos dos filhos e netos. Obrigado por ser a maior incentivadora de todos os meus sonhos. 


\section{Agradecimentos}

Ao Prof.Dr. José Carlos Farias Alves Filho, por aceitar me orientar, pela confiança, orientação de qualidade, pelos ensinamentos e pelos desafios propostos.

Aos amigos do laboratório de Inflamação e Dor, por todo o apoio e incentivo durante esses dois anos.

Aos amigos que ganhei de presente em Ribeirão.

Aos técnicos do LID, Giuliana, Kátia, Serginho, Marquinhos, Diva e Ieda, pela ajuda na organização e limpeza do laboratório, além do agradável convívio.

À Ana Cristine, pelo apoio, estando sempre solícita em ajudar.

Às agências de fomento, Coordenação de Aperfeiçoamento Pessoal de Nível Superior (CAPES), Conselho Nacional de Desenvolvimento Tecnológico e Científico (CNPQ), Fundação de Amparo à Pesquisa do Estado de São Paulo (FAPESP) e ao Center for Research in Inflammatory Diseases (CRID) pelo apoio financeiro fundamental para desenvolvimento deste trabalho. 



\section{SUMÁRIO}

LISTA DE FIGURAS 10

RESUMO 13

ABSTRACT 15

INTRODUÇÃO 17

1. INTRODUÇÃO 18

1.1 PELE: CARCATERÍSTICAS GERAIS E FUNÇÕES 18

1.2 PSORÍASE: CARACTERÍSTICAS GERAIS E FISIOPATOLOGIA 19

1.3 ALARMINAS: CARACTERÍSTICAS GERAIS E FUNÇÕES 22

1.4 ALARMINA S100A9: CARACTERÍSTICAS E FUNÇÕES 23

2. OBJETIVOS 26

2.1 OBJETIVO GERAL 26

2.2 OBJETIVOS ESPECÍFICOS 26

MATERIAIS E MÉTODOS 27

3. MATERIAIS E MÉTODOS 28

3.1. COLETA DA PELE DE PACIENTES 28

3.2. ANIMAIS 28

3.3. MODELO EXPERIMENTAL DE PSORÍASE 29

3.4. TRATAMENTO COM PAQUINOMODE 29

3.5. AVALIAÇÃO DA EXPRESSÃO GÊNICA 29

3.6. ANÁLISE DE BIOINFORMÁTICA 31

3.7. AVALIAÇÃO PROTEICA POR IMUNOBLOTTING 31

3.8. CULTURA DE CÉLULAS DENDRÍTICAS 32

3.9. IMUNOFLUORESCÊNCIA 32 
3.11. ELISA 33

3.12. COLETA E PROCESSAMENTO DOS LINFONODOS: PREPARO DA SUSPENSÃO CELULAR (ex vivo) 33

3.13. CITOMETRIA DE FLUXO 34

3.14. GERAÇÃO DE ANIMAIS QUIMERAS 34

3.15. ANÁLISE ESTÁTISTICA 35

4. RESULTADOS 37

4.1. AUMENTO DA EXPRESSÃO DE S100A9 ESTÁ CORRELACIONADO POSITIVAMENTE COM O AUMENTO DA EXPRESSÃO DE GENES ENVOLVIDOS COM A PATOGÊNESE DA PSORÍASE EM PACIENTES 37

4.1. AUMENTO DA EXPRESSÃO DE S100A9 NO MODELO DE PSORÍASE EXPERIMENTAL 41

4.2. AUSÊNCIA OU INIBIÇÃO FARMACOLÓGICA DE S100A9 DIMINUEM A INFLAMAÇÃO E ESPESSAMENTO DA EPIDERME NO MODELO DE PSORÍASE EXPERIMENTAL 45

4.4 AUSÊNCIA GENÉTICA OU INIBIÇÃO FARMACOLÓGICA DE S100A9 DIMINUEM A FREQUENCIA DE LINFÓCITOS TCRTA IL-17+, MAS NÃO ALTERAM A FREQUÊNCIA DE LINFÓCITOS TCD4 IL7+ E LTCD4 FOXP3+_ 49

4.5. CÉLULAS MIELÓIDES E CÉLULAS EPITELIAIS PRODUZEM S100A9, E AMBAS CONTRIBUEM PARA O AUMENTO DO ESPESSAMENTO DA EPIDERME 52

4.6. A AUSÊNCIA GENÉTICA DE S100A9 DIMINUI A EXPRESSÃO GÊNICA DE EXPRESSÃO DE IL-23 NA PELE E A FREQUÊNCIA DE CÉLULAS CD11C+ PRODUTORAS DE IL-23, APÓS APLICAÇÃO TÓPICA DE IMQ 55

4.7. S100A9 INDUZ A PRODUÇÃO DE IL-6 EM CÉLULAS DENDRÍTICAS DE MANEIRA DEPENDENTE DE TLR4 57

5. DISCUSSÃO 60

6. CONCLUSÃO 71 


\section{LISTA DE FIGURAS}

Figura 1. A expressão gênica de S100A9 está aumentada na pele lesionada de pacientes com psoríase. 38

Figura 2. A expressão gênica de S100A9 está correlacionada positivamente com genes associados a psoríase na pele lesionada de pacientes com psoríase.

Figura 3. A expressão proteica de S100A9 está aumentada e localizada principalmente na epiderme na pele lesionada de pacientes com psoríase. 40

Figura 4. A expressão de S100A9 e outros genes relacionados com proliferação de queratinócitos e respostas pró-inflamatórias estão aumentados na pele após aplicação tópica de $\begin{array}{lllll}\text { IMQ no dorso camundongos } & \text { WT. }\end{array}$

Figura 5. A expressão proteica de S100A9 está aumentada e co-localizada principalmente na epiderme na pele de camundongos WT após aplicação tópica de IMQ.

Figura 6. A expressão de S100A9 e outros genes relacionados com respostas pró-inflamatórias estão aumentados no linfonodo após aplicação tópica de IMQ no dorso de camundongos WT.

Figura 7. A expressão proteica de S100A9 está aumentada e co-localizada com células CD11c+ nos linfonodos drenantes da pele de camundongos WT após aplicação tópica de IMQ.

Figura 8. A ausência genética de S100A9 diminui a espessura da epiderme, diminui a formação de vasos e reduz a inflamação após aplicação tópica de Imiquimode 5\%. 
Figura 9. A inibição farmacológica de S100A9 diminui a espessura da epiderme, diminui a formação de vasos e reduz a inflamação após aplicação tópica de Imiquimode

Figura 10. A ausência genética de S100A9 diminui a frequência de linfócitos TCR $\gamma \delta$ IL-17+ nos linfonodos drenantes da pele, mas não altera a frequência de Linfócitos TCD4 IL-17+ e Linfócitos $\quad$ TCD4 $\quad$ FoxP3+ após aplicação tópica IMQ 50

Figura 11. A Inibição Farmacológica de S100A9 diminui a frequência de Linfócitos TCR $\gamma \delta$ IL-17+ nos linfonodos drenantes da pele, mas não altera a frequência de Linfócitos TCD4 IL17+ e Linfócitos TCD4 FoxP3+ após aplicação tópica de IMQ. 52

Figura 12. A ausência genética de S100A9 ou inibição farmacológica diminui a espessura da epiderme e reduz a inflamação após aplicação tópica de IMQ na orelha. 54

Figura 13. Tanto as células epiteliais quanto as células mielóides, produtoras de s100a9, são importantes para o aumento do espessamento da epiderme, após aplicação de IMQ 56

Figura 14. A ausência ou inibição farmacológica de S100A9 diminuem a expressão gênica de expressão de $i l-23$ na pele e a frequência de células cd11c+ produtoras de IL-23, após aplicação de

IMQ $5 \%$. 58

Figura 15. S100A9 induz a produção de IL-6 em células dendríticas derivadas da medula óssea, de maneira dependente de TLR4.

Esquema1. Geração dos animais quimera. 35 



\section{RESUMO}

MELO, BMS. Alarmina S100A9: um mediador crítico no desenvolvimneto da psoríase. Dissertação de mestrado. Faculdade de Medicina de Ribeirão Preto, Universidade de São Paulo, Ribeirão Preto, SP, Brasil, 2017,77.

A psoríase (Ps) é uma doença inflamatória crônica-imunomediada da pele, caracterizada por proliferação acentuada e diferenciação anormal de queratinócitos e aumento do infiltrado de células inflamatórias na derme. S100A9 é um alarmina que é produzida por queratinócitos e células mielóides em condições inflamatórias. No entanto, o papel desta molécula no desenvolvimento e manutenção da resposta inflamatória da Ps permanece desconhecida. Nesso objeitvo foi investigar o papel de S100A9 no desenvolvimento da psoríase. Análises de bioinformática de um banco de dados disponível on-line contendo valores de expressão de gênica de humanos mostrou que a expressão de S100A9 está aumentada pele lesionada de pacientes com Ps. Esses dados foram confirmados por imunofluorescência e Western blot onde foi observado um aumento na expressão de S100A9 na pele lesionada de pacientes com Ps, em comparação com amostras de pele não lesionada desses mesmo pacientes. Estes níveis de S100A9 foram positivamente correlacionados com a expressão de queratina-17, um marcador de ativação de queratinócitos. Para investigar o papel do S100A9 no desenvolvimento de Ps, autilizamos o modelo de Ps induzido por aplicação tópica de imiquimode (IMQ) nas costas de de camundongos WT, S100A9 - / - ou camundonos previamente tratados com paquinimod (10mg / kg, vo ), um quelante de S100A9. A exposição ao IMQ induziu o aumento da expresão gênica de $S 100 a 9$ e proteica de forma rápida e dependente do tempo na pele e nos linfonodos drenantes da pele, e esse aumento permaneceu elevado até o final do experimento ( $6^{\circ}$ dia). Notavelmente, a inflamação, e espessura da pele foram significativamente reduzidas em camundongos tratados com PAQ ou camundongos S100A9 -/- em comparação com camundongos WT. Os parâmetros histológicos confirmam a redução da espessura da epiderme, mostrada por seções histológicas coradas com HE. Para determinar quais células produtoras de S100A9 contribuem para o desenvolvimento de Ps, realizamos uma quimera e mostramos que ambos os queratinócitos e células mieloides são importantes para a produção de s100a9 e contribuem para o desenvolvimento da psoríase. No entanto os queratinócitos parecem ser mais importantes no aumento da espessua e na lesão da pele. Além disso, a expressão de $I l 23$, na pele de animais S100A9 -/- ou tratados com PAQ foi reduzida, o que poderia explicar a redução das linfócitos T gamma-delta IL-17 nos linfonodos desses mesmos camundongos. Nosso trabalho mostrou que o alarmina S100A9 desempenha um papel importante no 
desenvolvimento da psoríase. Assim, S100A9 poderia ser uma estratégia futura para o tratamento farmacológico da psoríase. Além disso essa proteína poderia ser usada como marcador da atividade da doença.

Palavras chaves: Psoríase; S1009. 


\begin{abstract}
MELO, BMS. Alarmin S100A9: a key driver in the development of psoriasis Masters dissertation. Faculty of Medicine of Ribeirão Preto, University of São Paulo, Riberião Preto, SP, 2017,104. 77.
\end{abstract}

Psoriasis (Ps) is an immune-mediated chronic inflammatory skin disease, characterized by accentuated proliferation and abnormal differentiation of keratinocytes and infiltration of inflammatory cells in the dermis. S100A9 is an alarmin that is produced by keratinocytes and myeloid cells in inflammatory conditions. However, the role of this molecule in the development and maintenance of the inflammatory response in Ps remains not well understood. Herein, we investigated the role of S100A9 in the development of psoriasis. Bioinformatical analysis of an online database containing human gene expression information showed that the s100a9 is overexpressed in lesional skin from Ps patients. These data were confirmed by immunofluorescence and western blot that showed an overexpression of s100a9 in the lesional skin from Ps patients compared with paired samples of nonlesional psoriatic skin. These levels of s100a9 were positively correlated with the expression of keratin-17, a keratinocyte activation marker. To investigate the role of S100A9 in the development of Ps, psoriasis-like skin inflammation was induced by topical application of imiquimod (IMQ) on the back skin of S100A9-deficient mice $\left(\right.$ S100A9 $\left.{ }^{-/-}\right)$or paquinimod $(10 \mathrm{mg} / \mathrm{kg}$, v.o) pretreated mice. IMQ exposure induced s100a9 mRNA and S100A9 protein expression in a rapid and time-dependent manner in the skin and lymph node of mice and remained elevated until the end of the experiment ( $6^{\text {th }}$ day). Notably, inflammation, assessed by epidermal thickness measurement and H\&E-stained histological sections, was significantly reduced in $5100 \mathrm{~A} 9^{-/-}$or paquinimod treated-mice compared with wild-type (WT) control mice. To determine which S100A9producing cell contributes to the Ps development we performed a chimera and showed that both keratinocytes and myeloid cells are important for the production of s100a9 and contribute to the development of psoriasis. However keratinocytes seems to be most important to development of lesion skin. Moreover, the expression of $I L-23$, in the skin, was reduced, which might explain the reduction of IL-17-producing gamma-delta T cells in the lymph nodes of S100A9-- or paquinimod-treated mice. We showed that the alarmin S100a9 plays an important role in the development of psoriasis. Thus, targeting S100A9 could be a future strategy for pharmacological treatment of psoriasis and this protein can be used as a marker of disease activity. 
Keywords: Psoriasis; S1009. 
INTRODUÇÃO 


\section{INTRODUÇÃO}

\subsection{PELE: CARCATERÍSTICAS GERAIS E FUNÇÕES}

A pele reveste a superfície do corpo, sendo o maior órgão do corpo humano e a principal barreira física entre o corpo e o meio ambiente. A pele é considerada um dos principais componentes da imunidade inata, sendo a primeira linha de defesa contra patógenos microbianos, e lesões físicas e químicas (PROKSC, 2008). Essa defesa da pele pode ser mediada por várias substâncias, incluindo os peptídeos antimicrobianos (PAMs), que são um grupo de moléculas associadas à defesa contra alguns patógenos. Estes PAMs podem ser produzidos por células epiteliais e células mielóides. (GANZ, 2003; HANCOCK, 2006). Além disso a pele é composta por um conjunto diferenciado de células com funções especializadas que contribuem na proteção do nosso corpo (NESTLE, 2009).

Dentre as principais camadas da pele estão a epiderme, derme e a hipoderme (WILLIAMS e KUPPER, 1996; CHUONG et al., 2002). A camada superficial ou mais externa, chamada epiderme, é formada por células epiteliais estratificadas que estão sobre a camada do tecido conectivo, também conhecido de derme. Aproximadamente $90 \%$ da epiderme é constituída de queratinócitos que são as células responsáveis pela formação do epitélio estratificado pavimentoso. Estas células possuem este nome devido a sua função essencial, que é produção de queratina, uma proteína que preenche as células mais superficiais da epiderme para formar a camada córnea. Além disso, a epiderme contém outras células do sistema imune como as células de langerhans, que são a primeira célula dendrítica a ter contato com antígenos estranhos em caso de lesão do tecido (KOSTER e ROOP, 2004; NESTLE, 2009; KRUEGER e BOWCOCK).

A epiderme e a derme estão fixadas em uma camada composta por tecido adiposo: a hipoderme (KOSTER e ROOP, 2004; KUPPER e FUHLBRIGGE, 2004). A derme é composta por células residentes como as células dendríticas dermais, macrófagos, células dendríticas 
plasmocitóides, entre outras. Cada célula dessa é especializada e tem um papel estratégico na derme (NESTLE, 2009). Várias células dos sistema imune podem infiltrar essa região, como os neutrófilos, células dendríticas, linfócitos, através dos vasos sanguíneos e linfáticos. Estas células, em geral, desempenham um papel importante no controle de infecções por alguns micro-organismos ou alguns tipos de lesões, no entanto sob estímulo inflamatório crônico, podem ser geradas respostas exacerbadas que culminam na ativação desordenada de células do sistema imune e de células epiteliais, que podem culminar no surgimento de doenças inflamatórias, a exemplo da psoríase. (RYAN, 2004; WELSS, 2004).

\subsection{PSORÍASE: CARACTERÍSTICAS GERAIS E FISIOPATOLOGIA}

A psoríase é uma doença inflamatória crônica não transmissível e recorrente da pele, afetando entre 2 a 5\% da população mundial (DUFFIN, 2008; KAÇAR, 2010; ELKAYAM, 2000). Esta doença apresenta etiologia multifatorial, resultante de uma complexa interação entre fatores genéticos, ambientais e sistêmicos, o que leva a uma desordem de células da derme, epiderme e do sistema imune, gerando um amplo espectro de manifestações clínicas com gravidade variável (DUFFIN, 2008; KRUEGER, 2005).

A psoríase é a desordem autoimune mais prevalente em humano, sendo mais prevalente em populações caucasianas (1,5-3\%), quando comparado à população negra $(0,3$ a $0,7 \%)$ (CAMPALANI, E. 2011). Apesar de poder se manifestar em qualquer idade, estão documentadas duas fases etárias do aparecimento da doença, reforçando o que é conhecido como distribuição bimodal. A primeira fase ocorre em torno de 15 a 20 anos de idade e a segunda fase em torno de 50 a 60 anos de idade (SABAT, 2011). A psoríase, em geral, é uma doença prevalente igualmente em ambos os sexos, embora estudos recentes mostrem que as formas mais severas da doença se manifestem mais em homens do que mulheres e estas desenvolvem a doença mais cedo (HAGG, 2013; DILÚVIO, 2005). 
Sabe-se que o envolvimento de fatores genéticos, ambientais e alterações emocionais podem levar à desregulação do sistema imunológico, culminando nas manifestações clínicas cutâneas e articulares características da doença. A presença de alguns padrões de Antígenos Leucocitários Humanos (HLA), bem como o HLA-B13, HLA-B17, HLA-B37, HLA-Bw16, HLA-Bw57 e HLA-DR7, atribuem um risco muito alto de desenvolvimento da psoríase. O HLA-Cw6 parece ser o mais importante, estando presente em mais de $80 \%$ dos casos de psoríase tipo I (início precoce) (RUIZ, 2012; CARNEIRO, 2007; ORTONNE, 1996; BERTHJONES, 2005). Outros estudos identificaram o lócus de suscetibilidade para a psoríase (PSORS 1-9), localizado no cromossomo 6. Porém, o lócus que apresenta maior destaque e é sugerido como o mais relevante, é o lócus 1 , sendo responsável por até $50 \%$ da contribuição genética da psoríase (ELDER, 2001; VALDIMARSSON, 2007; ALMEIDA I.M.M, 2011; CARNEIRO, 2007).

Dentre os fatores ambientais envolvidos com o surgimento da psoríase, estão o uso de álcool, do tabaco, drogas como os $\beta$-bloqueadores e alguns agentes contra a malária. Os contraceptivos orais, ocasionalmente, parecem diminuir a gravidade da psoríase e a infecção por HIV, por sua vez, agrava (KRUEGER e ELLIS, 2005; RODRIGUES e TEIXEIRA, 2009). Especialistas e estudos apontam o estresse fisiológico e físico, como um dos principais desencadeadores da psoríase. (BERTH-JONES, 2005; RODRIGUES e TEIXEIRA, 2009). Recentemente, índices de massa corporal alto (acima dos 30) foram correlacionados como sendo um fator etiológico da doença, estando associados a casos de psoríase severa (GUTTMAN-YASSKY et al., 2011). Infecções do trato respiratório superior, como amigdalites e faringites por streptococcus, são os únicos fatores exógenos associados comprovadamente à indução e agravamento da doença. As toxinas dessa bactéria atuam como superantígenos, resultando numa complexa cascata de ativação de células $\mathrm{T}$, células de Langerhans e queratinócitos (RODRIGUES e TEIXEIRA, 2009). 
Até o início dos anos 90, acreditava-se que o principal mecanismo de patogênese da doença estava relacionado somente com a diferenciação e proliferação de queratinócitos (DA SILVA A.C.A, 2011), porém hoje sabe-se que existe uma participação direta de células do sistema imune. A ativação recorrente de células dendríticas, linfócitos $\mathrm{T}$ e outras células, combinada com uma falha de tolerância, leva a um processo contínuo de inflamação, culminando em alterações no nível da epiderme como hiperplasia com acantose, hiperqueratose, paraqueratose e hipogranulose (SCHON, M. P. 2005; SABAT, R. 2007). Todas essas alterações são consequência de uma disfunção no processo de cornificação, onde existe um aumento da atividade mitótica dos queratinócitos. Estes migram da camada basal para a camada córnea mais cedo, em torno de 5 dias, em vez 28 a 30 dias (SABAT, R. 2007), o que explica o espessamento e descamação continuada da pele lesionada.

Em conjunto, o desenvolvimento da psoríase possui uma participação de diferentes grupos celulares e moléculas, que contribuem para o desenvolvimento da psoríase. Vários trabalhos já demonstraram que as células dendríticas e linfócitos $\mathrm{T}$ são cruciais no desenvolvimento da psoríase (DI CESARE, 2009; WEAVER, 2007; BETTELLI, 2007; KASTELEIN, 2007). Muitos dos mecanismos sobre a fisiopatologia da psoríase ainda são obscuros, mas alguns estudos mostram que agentes infecciosos, traumas, algumas drogas ou estresse, em associação com fatores genéticos podem levar a ativação ou dano de queratinócitos e induzir a liberação de DNA próprio junto com peptídeos antimicrobianos (AMPs), além de citocinas como IL-1 $\beta$, TNF- $\alpha$ e IL-6. Um dos peptídeos antimicrobianos mais estudados é a catelicidina LL-37. A LL-37 pode interagir com DNA próprio e esse complexo imunogênico é reconhecido por células dendríticas plasmocitóides (pDC), que produzem interferon alfa (IFN$\alpha)$. Este IFN- $\alpha$ em associação com as citocinas liberadas pelas células epiteliais ativam diretamente células dendríticas da derme, que migram para o linfonodo e produzem citocinas como IL-12 e IL-23, as quais polarizam linfócitos TCD4 naives em linfócitos Th1 e THh7, 
respectivamente. Além disso, IL-23 é um sinal importante para a ativação de linfócitos TCR $\gamma \delta$ produtores de IL-17. Uma vez ativadas, essas células migram a favor de um gradiente de quimiocinas, onde amplificam o processo inflamatório. Linfócitos Th1 também produzem TNF e IFN- $\gamma$ que ativam células dendríticas da derme e atuam diretamente nos queratinócitos, respectivamente. linfócitos TH17 e linfócitos TCR $\gamma \delta$ produzem IL-17A, IL-17F e IL-22 que atuam diretamente nas ativação de células epiteliais via receptores de IL-17 e IL-22. Uma vez ativadas, essas células proliferam de forma acentuda, o que culmina na produção de mediadores pró-inflamatórios como o CXCL-8 e outros quimioatraentes, que recrutam neutrófilos e outras células. Além disso, quando ativados, os queratinócitos podem produzir substâncias como as beta defensinas e proteínas da família S100, que são comumente associadas com doenças inflamatórias, inclusive a psoríase (GREB, 2016; ZENZ, 2005; EHRCHEN, 2009; MARKOWITZ, 2013).

\subsection{ALARMINAS: CARACTERÍSTICAS GERAIS E FUNÇÕES}

Os Padrões moleculares associados a danos (DAMPs) ou alarminas são moléculas endógenas, cuja liberação se dá por mecanismos de estresse, lesão ou morte celular. Esses mediadores são rapidamente expressos ou secretados frente a estímulos infecciosos ou inflamatórios. Uma vez liberados, podem ativar mecanismos imunes e inflamatórios através dos receptores de imunidade inata TLRs. Os receptores TLR2 e TLR4, são classicamente descritos pelo reconhecimento de estruturas bacterianas, e esses receptores também estão associados com o reconhecimento dessas alarminas. Essas alarminas tem função similiar aos padrões moleculares associados a danos (PAMPs), em gerar respostas pró-inflamatórias, via sinalização desses receptores de conhecimento padrão. Dentre as principais alarminas descritas temos a HMGB1, SAP130, DNA, IL-1 $\alpha$, IL-33, algumas proteínas da Família S100, entre 
outras ((MEDIZHITOV; PRESTON-HURLBURT; JANEWAY 1977, LOTZE, 2007; FOELL, 2007).

\subsection{ALARMINA S100A9: CARACTERÍSTICAS E FUNÇÕES}

As proteínas da família S100 tem emergido como moléculas críticas da imunidade inata, importantes na participação de várias desordens inflamatórias, metabólicas e neoplásicas. São assim chamadas pois são 100\% solúveis em sulfato de amônia (ZIMMER, 1995). Essa família consiste em 24 membros funcionais distribuídos em três subgrupos: proteínas com funções intracelulares, proteínas intra e extracelulares e proteínas que só exercem efeitos extracelulares. As proteínas da família S100 são expressas somente em vertebrados. Dentro da célula, muitas dessas proteínas estão associadas com a progressão do ciclo celular, regulação de eventos de fosforilação, interação membrana-citoesqueleto, transdução de sinais e metabolismo energético (STEINBAKK, 1990; SOHNLE, COLLINS-LECH; WIESSNER, 1991; RAMMES, 1997). Algumas proteínas S100A podem ser secretadas ou liberadas e regulam a função da célula de maneira autócrina e parácrina. A localização e estrutura de cada proteína permite que cada uma tenha um papel diferencial, embora muitas possam desempenhar a mesma função em uma mesma célula. Roth e colaboradores demostraram que S100A7, S100A8, S100A9 e S100A12 estão aumentadas em condições inflamatórias como artrite psoriásica, artrite reumatóide e psoríase. (EHRCHEN, 2009).

A proteína S100A9 é codificada pelo gene humano S100A9. Os genes da família S100A estão localizados no cromossomo 1q21 em humanos. A proteína S100A9 apresenta baixo peso molecular e umas das suas principais características é a presença de dois sítios ligantes de cálcio intracelular (ODINK, 1987; EDGEWORT, 1991; HESSIAN, 1993).

Vários trabalhos já demostraram o papel inflamatório de S100A9. Esta apresenta um papel na migração, adesão e transmigração de leucócitos dos vasos sanguíneos (RYCKMAN, 2003; SCHNEKENBURGER, 2008). Erchen e colaboradores demonstraram que S100A9 
murino foi utilizada como fator quimiotático para macrófagos peritoneais e alveolares e S100A9 humano foi importante para atrair neutrófilos (EHRCHEN, 2009). Foi demonstrado também que S100A9 induz a produção de TNF- $\alpha$,IL-1 $\beta$ e IL-6 em macrófagos via ativação de NF-kB (SUNAHORI, 2006). S100A9 também estimula a liberação de IL-8 em células epiteliais (AHMAD, 2003). Na presença de Zn2+ e Ca2+ S100A9 é um ligante de RAGE e TLR-4 e pode contribuir para a patogênese de doenças autoimunes (LECLERC, 2003).

Essas proteínas S00A9 começaram a receber maior interesse desde que foram descritas como padrões moleculares associados a danos (DAMPs) (FOELL, 2007; SCHIOPU, 2012). Esses mediadores podem ser produzidas por células mielóides, tais como neutrófilos, macrófagos e monócitos, bem como células epiteliais (ZENZ, 2005; EHRCHEN, 2009; MARKOWITZ, 2013). Estas atuam via TLR4 e RAGE. NUKUI e colaboradores (2008) demonstraram que proteínas S100A9 podem induzir a expressão de quimiocinas como CXCL1, 2, 3, CXCL-8, IL-1 e TNF- $\alpha$, além de induzir a proliferação de queratinócitos in vitro. SCHONTHALER e colaboradores mostraram que o complexo S100A8-S100A9, também conhecido por calprotectina é crítico para o espessamento da pele utilizando modelo de psoríase experimental por Imiquimode. Além disso, a proteína S100A9 já foi encontrada tanto no soro quanto em lesão de pacientes com psoríase, porém a função dessa molécula no desenvolvimento da doença permanece pouco compreendida (CHIMENTI, 2016; WILSMANN-THEIS, 2016). 
OBJETIVOS 


\section{OBJETIVOS}

\subsection{OBJETIVO GERAL}

Avaliar o papel de S100A9 na imunopatogênese da psoríase

\subsection{OBJETIVOS ESPECÍFICOS}

2.2.1. Avaliar a expressão de S100A9 na pele de pacientes com psoríase;

2.2.2. Caracterizar a expressão de S1009 no modelo de psoríase induzido por imiquimode;

2.2.3. Avaliar a relevância biológica de S100A9 in vivo utilizando o modelo de psoríase

experimental;

2.2.4. Avaliar quais perfis celulares produtores de S100A9 são mais importantes no modelo de psoríase experimental;

2.2.5. Avaliar os mecanismos pelo qual S100A9 contribui na imunopatogênese da psoríase;

2.2.6. Avaliar a resposta induzida por S100A9 in vitro em células dendríticas. 
MATERIAIS E MÉTODOS 


\section{MATERIAIS E MÉTODOS}

\subsection{COLETA DA PELE DE PACIENTES}

Foram escolhidos pacientes com psoríase vulgar ativa. Inicialmente foi aplicada anestesia local e posteriormente retirado $4 \mathrm{~mm}$ de pele lesiona e não lesionada com punch descartável. As amostras foram coletadas pela equipe médica da divisão de dermatologia, do hospital das clínicas de Ribeirão Preto. Após a coleta, as amostras foram armazenadas em soluções específicas para processamento e posterior armazenamento em freezer -70. Os pacientes foram informados sobre o objetivo da pesquisa e participaram por livre e espontânea vontade. Os mesmos assinaram um termo de consentimento livre esclarecido. A pesquisa foi aprovada pelo comitê de ética em pesquisa clínica do Hospital das Clínicas e da Faculdade de Medicina de Ribeirão Preto - USP (Certificado número: 65644117.1.0000.5440).

\subsection{ANIMAIS}

Foram utilizados animais do background C57BL/6. Além de animais wild type, também foram utilizados animais nocautes totais para S100A9, provenientes do biotério de camundongos especiais do departamento de genética da Faculdade de Medicina de Ribeirão Preto da Universidade de São Paulo (FMRP USP). A maioria dos experimentos foram realizados em machos. Todos os animais para experimentação foram mantidos no biotério do Departamento de Farmacologia da FMRP-USP sob condições de temperatura de $23-25^{\circ} \mathrm{C}$, ciclo de claro/escuro de $12 \mathrm{~h}$, com aceso livre a água e ração. Os protocolos experimentais realizados neste trabalho estão de acordo com os Princípios éticos de experimentação animal, adotado pelo Colégio Brasileiro de Experimentação Animal (COBEA) e foi aprovado pela Comissão de Ética em Experimentação Animal (CETEA) do Hospital das Clínicas e da Faculdade de Medicina de

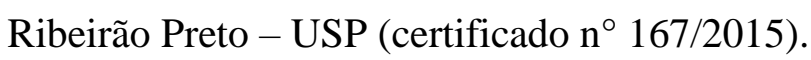




\subsection{MODELO EXPERIMENTAL DE PSORÍASE}

Neste modelo, foram utilizados camundongos do background C57BL/6. O pêlo do dorso foi retirado com máquina e creme depilatório "veet". Dois dias após o primeiro procedimento, aplicamsr imiquimode sobre o dorso durante 6 dias ininterruptos, sendo a dose diária de 3,25 mg de imiquimode 5\%/animal (Ixium $\left.{ }^{\circledR}\right)$. O escore clínico dos animais foi monitorado diariamente utilizando-se a espessura da pele (paquímetro) como parâmetro principal.

\subsection{TRATAMENTO COM PAQUINOMODE}

O tratamento com paquinimode foi realizado um dia antes da indução com IMQ, e todos os dias até o dia 6 . A dose utilizada foi de $10 \mathrm{mg} / \mathrm{Kg}$ via oral, por gavagem.

\subsection{AVALIAÇÃO DA EXPRESSÃO GÊNICA}

A avaliação da expressão gênica foi realizada em células da pele de do linfonodo drenante da pele. O RNA total foi isolado utilizando o RNeasy Mini Kit (Qiagen), de acordo com as instruções do fabricante. O cDNA $(0,5 \mu \mathrm{g}$ of RNA) foi convertido através do high capacity cDNA RT Kit (Applied Biosystem), de acordo com as instruções do fabricante. O cDNA foi utilizado para Real-time PCR através de uso de SYBR Green Master mix (Thermofischer) and TaqMan (Applied Biosystems) e avaliados no Viia7 PCR system. Todos os dados foram normalizado pelos valores do gene endógeno (GAPDH). Os resultados foram analisados com base no valor de CT (Cicle Threshold - ou ciclo limiar). A fórmula utilizada para análise dos resultados foi $2^{-(\Delta \Delta \mathrm{Ct})}$, na qual $\Delta \Delta \mathrm{Ct}=\Delta \mathrm{Ct}$ amostra $-\Delta \mathrm{Ct}$ controle e $\Delta \mathrm{Ct}=\mathrm{CT}$ gene alvo - CT gene de referência endógeno (Gapdh). As sequências dos primers avaliados encontram-se abaixo.

\section{Gapdh}

Sense: CATCTTCTTGTGCAGTGCCA

Antisense: CGGCCAAATCCGTTCAC 
S100a8

Sense: AAATCACCATGCCCTCTACAAG

Antisense:CCACTTTTATCACCATCGCAA

S100a9

Sense: CAGCATAACCACCATCATCG

Antisense: GTCCTGGTTTGTGTCCAGGT

Lcn2

Sense: CCCCATCTCTGCTCACTGTC

Antisense: TTTTTCTGGACCGCATTG

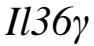

Sense: ATGGACACCCTACTTTGCTG;

Antisense: TGTCCGGGTGTGGTAAAACA);

Il23 (p19)

Sense: CACCTCCCTACTAGGACTCAGC

Antisense:CTGCCACTGCTGACTAGAAC

$I l 17 a$

Sense: GCTCCAGAAGGCCCTCAG

Antisense: CTTTCCCTCCGCATTGACA

I122

Sense: CAGCTCCTGTCACATCAGCGGT

Antisense: AGGTCCAGTTCCCCAATCGCCT

IL-1 $\beta$

Sense: TGACAGTGATGAGAATGACCTGTTC;

Antisense: TTGGAAGCAGCCCTTCATCT)

Il-6

Sense: TTCCTACCCCAATTTCCAAT

Antisense: CCTTCTGTGACTCCAGCTTATC

Tnfa 
Sense: TGTGCTCAGAGCTTTCAACAA

Antisense: CTTGATGGTGGTGCATGAGA

Os valor relativo de expressão gênica foi representado na forma de heat map, usando a plataforma online 'Morpheus - broad institute'. O valor mínimo e máximo representa a mediana de cada alvo expresso.

\subsection{ANÁLISE DE BIOINFORMÁTICA}

Foi feito o download do GEO data set GSE13355, disponível no site do NCBI. Após isso foram retirados os efeitos de lote usando o pacote sva (LEEK, 2007; LEEK, 2008). Os dados foram normalizados utilizando a função 'Robust Multi Array Average' do pacote affy (GAUTIER, 2004). O controle de qualidade foi feito utilizando o pacote 'arrayQualityMetrics' do bioconductor. Os dados normalizados foram submetidos à análise de expressão diferencial com o pacote limma do bioconductor e estão representados no volcano plot. Um subconjunto de genes normalizados (KRT17, LCN2, IL22, IL36y e STAT3 e IL23A), foram correlacionados com S100A9 utilizando a correlação de Sperman. As análises estatísticas foram feitas usando o R.

\subsection{AVALIAÇÃO PROTEICA POR IMUNOBLOTTING}

O lisado das células foi preparado com tampão de lise (Pierce RIPA buffer, Thermo Scientific) com inibidor de protease (complete cocktail) e inibidor de fosfatase PhosSTOP, ambos da Roche Applied Science. As amostras foram quantificadas (kit de BCA, sigma) de acordo com as instruções do fabricante e de $10 \mathrm{ug}$ de proteínas foram utilizadas na eletroforese. Para separar as amostras por peso molecular foi realizada eletroforese em gel de poliacrilamida SDS e transferidas para membrana de nitrocelulose (Merck Millipore) e bloqueadas por 1 hora a temperatura ambiente com leite 5\%. Para a marcação foram utilizados os seguintes anticorpos diluidos em BSA 5\%: S100A9 (R (R\&D 1:1000) GAPDH (Sigma 1:10000). Anticorpos antigoat e anti-rabbit com peroxidase (Cell signaling) foram utilizado na concentração de 1:5000 
diluidos em leite 5\%/TBST. O sinal foi detectado com ECL prime (GE Healthcare) no Chemidoc imaging systems (Bio-Rad Laboratories).

\subsection{CULTURA DE CÉLULAS DENDRÍTICAS}

DCs foram geradas a partir da diferenciação de células da medula óssea. Para isso, os animais foram mortos e o osso fêmur cuidadosamente dissecado. Em ambiente estéril, as epífises ósseas foram cortadas e uma agulha de $20 \mathrm{~g}$, acoplada à uma seringa preenchida com RPMI-1640 completo (suplementado com $10 \%$ de soro fetal bovino, glutamina (2 mM), estreptomicina- $0,01 \mathrm{mg} / \mathrm{mL}$; penicilina- $10 \mathrm{U} / \mathrm{mL}$; antifungico- anfotericina B- $30 \mu \mathrm{g} / \mathrm{mL}$ ), foi inserida em uma das extremidades. A seguir, foi realizada a lavagem da cavidade interna do osso removendo toda a medula óssea. As células foram adicionadas à placas de cultura na densidade de 2,0 x $10^{6}$ células/placa em um volume final de $10 \mathrm{~mL}$ de RPMI-1640 completo, suplementado com $20 \mathrm{ng} / \mathrm{mL}$ de GM-CSF (fator estimulante de colônia granulocíticamacrofágica). Após 3 dias, foram adicionados mais $10 \mathrm{~mL}$ de meio suplementado com a mesma concentração de GM-CSF. Ao final de 7 dias, as células foram coletadas da placa e transferidas para os animais quimeras gerados previamente. Nesse experimento foram utilizados animais WT e TLR4-/-.

\subsection{IMUNOFLUORESCÊNCIA}

Tecidos de camundongos ou biópsia de pacientes foram fixadas em uma solução de $4 \%$ de paraformol-aldeido em solução de tampão fosfato (PBS+4\%PFA). Após fixação, o material foi acondicionado em uma solução de sacorase 30\% em PBS (pH 7.4). Após esse precedimento, o tecido foi congelado em TissueTek e cortados em uma espessura de 6 micrometros no criostato. Após os cortes e respectivo preparo da lâmina, o material foi incubado 10 minutos com metanol P.A a $20^{\circ} \mathrm{C}$ e depois lavadas 3 vezes de 5 minutos em PBS. A seguir, as lâminas foram incubadas 
em uma solução de PBS suplementada com Glicina $(0,1 \mathrm{M})$ durante 30 minutos. Outra incubação foi realizada utilizando PBS suplementado com $2 \%$ albumina bovina sérica (BSA) e 0,2\% de Triton X100. Nesse ponto, o anticorpo purificado, anti-K17, anti-S100A9, anti-K14 (1:200, Abcam) foram adicionados e mantido overnight a $4^{\circ} \mathrm{C}$ e será submetido ao processo de lavagem. Após todo esse processo, o anticorpo secundário IgG goat anti-rabbit FITC, IgG monkey anti-goat e IgG monkey anti-rabbit (1:400) foram adicionados e incubados por 2 horas e submetidos ao processo de lavagem descrito acima. Por fim, as lamínulas foram introduzidas na lâmina juntamente com o meio de montagem Prolong ${ }^{\circledR}$ gold anti-fade reagent with DAPI. As imagens foram captadas utilizando o microscópio confocal Axio Observer combined with LSM 800 (Carl Zeiss Microscopy) e analizadas utilizando software Fiji by ImageJ.

\subsection{AVALIAÇÃO DO ESPESSAMENTO DA PELE}

O tecido da pele foi dissecado e dividido em corte longitudinais, separando em dois hemisférios que foram utilizados na histologia. A coloração de rotina Hematoxilina-Eosina (HE)foi realizada para uma observação geral das alterações histopatológicas.

\subsection{ELISA}

As quantificações de IL-6 foi realizada no sobrenadante da cultura de células dendríticas após 24 horas de estímulo com LPS, IMQ e S100A9. A quantificação desta citocinas foi realizada por método imunoenzimático (ELISA), conforme descrito pelo fabricante.

\subsection{COLETA E PROCESSAMENTO DOS LINFONODOS: PREPARO DA SUSPENSÃO CELULAR (ex vivo)}

Após os camundongos serem eutanasiados, os linfonodos drenantes da pele ou da orelha foram retirados, e colocado em tubo de propietileno de $15 \mathrm{ml}$ (Falcon® ) contendo $1 \mathrm{ml}$ de meio RPMI 1640 incompleto. A seguir, os órgãos foram divulssionados em peneira de propietileno 
(Falcon® - separador de células $-100 \mu \mathrm{m}$ ) com auxílio do êmbolo da seringa de $5 \mathrm{ml}$ (Plastipak®), formando uma única suspensão celular. As hemácias foram lisadas por choque hiposmótico utilizando um tampão de lise e uma nova centrifugação foi realizada. Subseqüentemente, as células do linfonodo foram ressuspensas em $1 \mathrm{ml}$ PBS cotendo 2\% de soro bovino fetal inativado. As células foram contadas em câmara de neubauer.

\subsection{CITOMETRIA DE FLUXO}

Foram utilizados anticorpos monoclonais especificos para antígenos murinos com fluorocromos para FACS das seguintes empresas e nas concentrações descritas: IL-17A PE (BD 1:200) CD4 APC (BD 1:200), TCR Foxp3 PE (BD 1:200) TCR $\gamma \delta$ FITC (BD 1:200). As células foram lavadas com PBS e incubadas com tampão de FACS (0.25\% BSA/2 mM EDTA em PBS) para marcação extracelular. Para marcação intracelular (IFN- $\gamma$, IL-13 and RL2), as células foram fixadas com 2\% PFA em PBS por 20 min no gelo. Estas células foram lavadas com tampão de permeabilização $(0.25 \%$ BSA/2 $\mathrm{mM}$ EDTA/0.5\% saponin em PBS). Previamente, para marcação de citocinas intracelulares, as células foram estímuladas com PMA

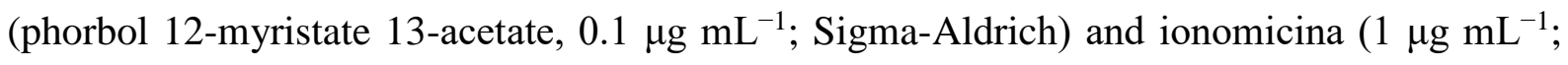
Sigma-Aldrich) por $2 \mathrm{~h}$, seguido de Brefeldin A $\left(5 \mu \mathrm{g} \mathrm{mL} \mathrm{L}^{-1}\right)$ por mais $2 \mathrm{~h}$. Para marcação de IL-17 e Foxp3 foi utilizado um kit de fixação/permeabilização (Affymetrix/eBioscience) e o procedimento foi de acordo com as intruções do fabricante. As células foram adquiradas nos seguintes aparelhos: CyAn ADP (Beckman Coulter), a LSR II (Becton Dickinson), FacsVerse (BD Biosciences). Os dados foram analisados no software FlowJo versão 10.0.

\subsection{GERAÇÃO DE ANIMAIS QUIMERAS}

Para a geração de animais quimeras, utilizamos dois diferentes protocolos os quais são descritos a seguir. Animais WT foram letalmente irradiados (7,0 Gy) e, suas células 
hematopoéticas reconstituídas com células da medula óssea $\left(5 \times 10^{6}\right.$ células, por via intravenosa) de camundongos WT ou S100A9-/-. Passados 2 meses após a reconstituição, foi iniciado o protocolo de indução de psoríase experimental (Esquema 1).
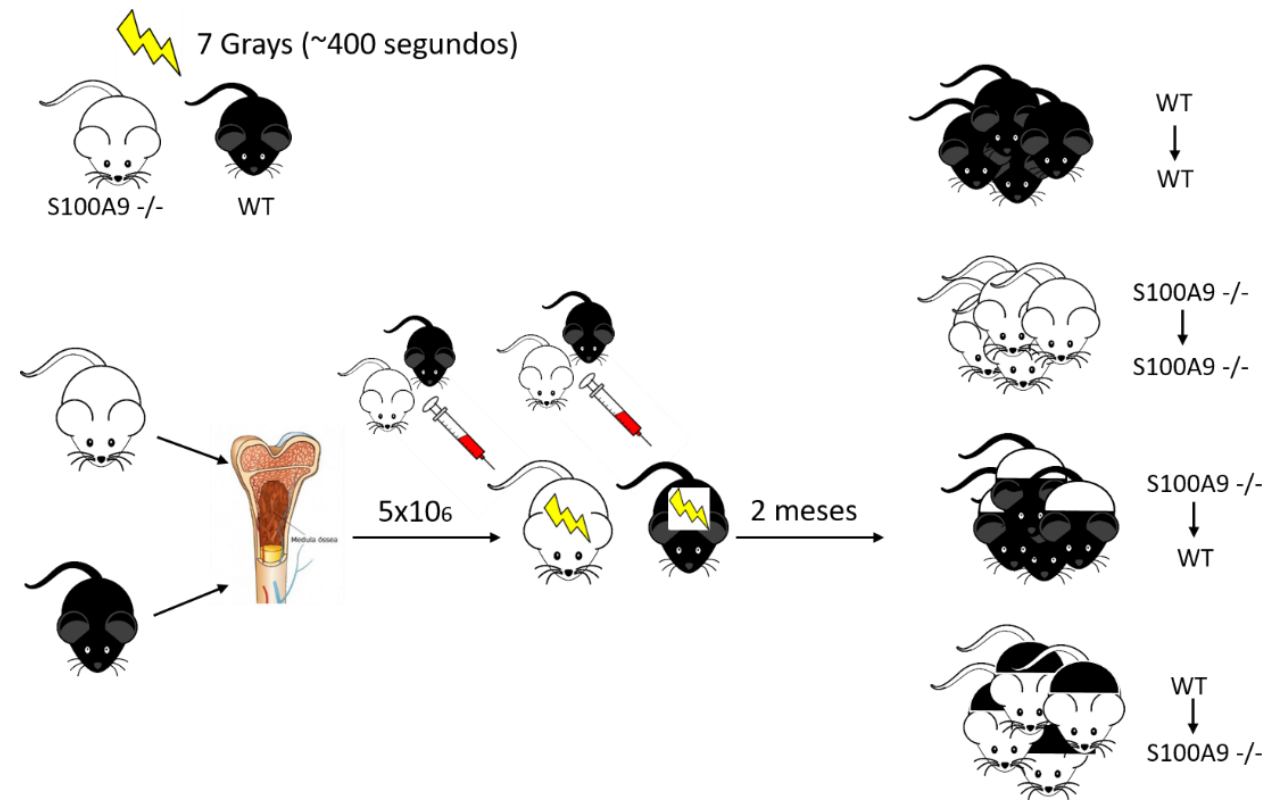

\subsection{ANÁLISE ESTÁTISTICA}

Os resultados foram representados como erro padrão da média (SEM) quando utilizarmos os médias dos experimentos respectivamente. Para comparação entre múltiplos grupos, foi utilizada a análise de variância (two-way ANOVA ou one-way ANOVA), seguida pelo pósteste de Bonferroni. Diferenças nos valores entre dois grupos. Todas as análises foram feitas com o auxílio do software GraphPad-Prism (GraphPad Software Inc., San Diego CA, EUA). Foram consideradas estatisticamente diferentes as amostras com o valor mínimo de $\mathrm{P}<0.05$. 
RESULTADO 


\section{RESULTADOS}

\subsection{AUMENTO DA EXPRESSÃO DE S100A9 ESTÁ CORRELACIONADO POSITIVAMENTE COM O AUMENTO DA EXPRESSÃO DE GENES ENVOLVIDOS COM A PATOGÊNESE DA PSORÍASE EM PACIENTES}

A proteína S100A9 está associada com algumas condições inflamatórias, como artrite reumatóide e psoríase (BENOIT, 2006; FROSCH, 2007). A expressão de S100A9 está aumentada na pele e no soro de pacientes com psoríase (WILSMANN-THEIS, 2016). A fim de validar esses dados, analisamos um banco de dados (GSE 13355) disponível online, que contém valores de expressão gênica da pele lesionada e não lesionada de pacientes com psoríase vulgar e pele de indivíduos saudáveis.

Após aplicar análises de bioinformática, demonstramos que não existe diferença na expressão gênica entre a pele de indivíduos saudáveis e pele não lesionada de indivíduos com psoríase (FIGURA 1A), no entanto existe uma diferença na expressão de vários genes, regulados positivamente ou negativamente, quando comparamos a pele de indivíduos saudáveis e pele lesionada de pacientes com psoríase ou pele não lesionada e lesionada de pacientes com psoríase. Nossos dados demonstram que a expressão de S100A9 está aumentada na pele (FIGURA 1 B e C). Validamos essas análises utilizando os valores brutos de expressão gênica de s100a9 do mesmo banco de dados, entre a pele de indivíduos saudáveis, pele lesionada e não lesionada de pacientes com psoríase, onde a expressão de S100A9 está aumentada na pele lesionada de pacientes com psoríase (FIGURA 1D). Utilizando outro banco de dados (GSE 14905), verificamos que a expressão de s100a9 também está aumentada, quando comparado com a pele não lesionada de pacientes com psoríase (FIGURA 1E). 

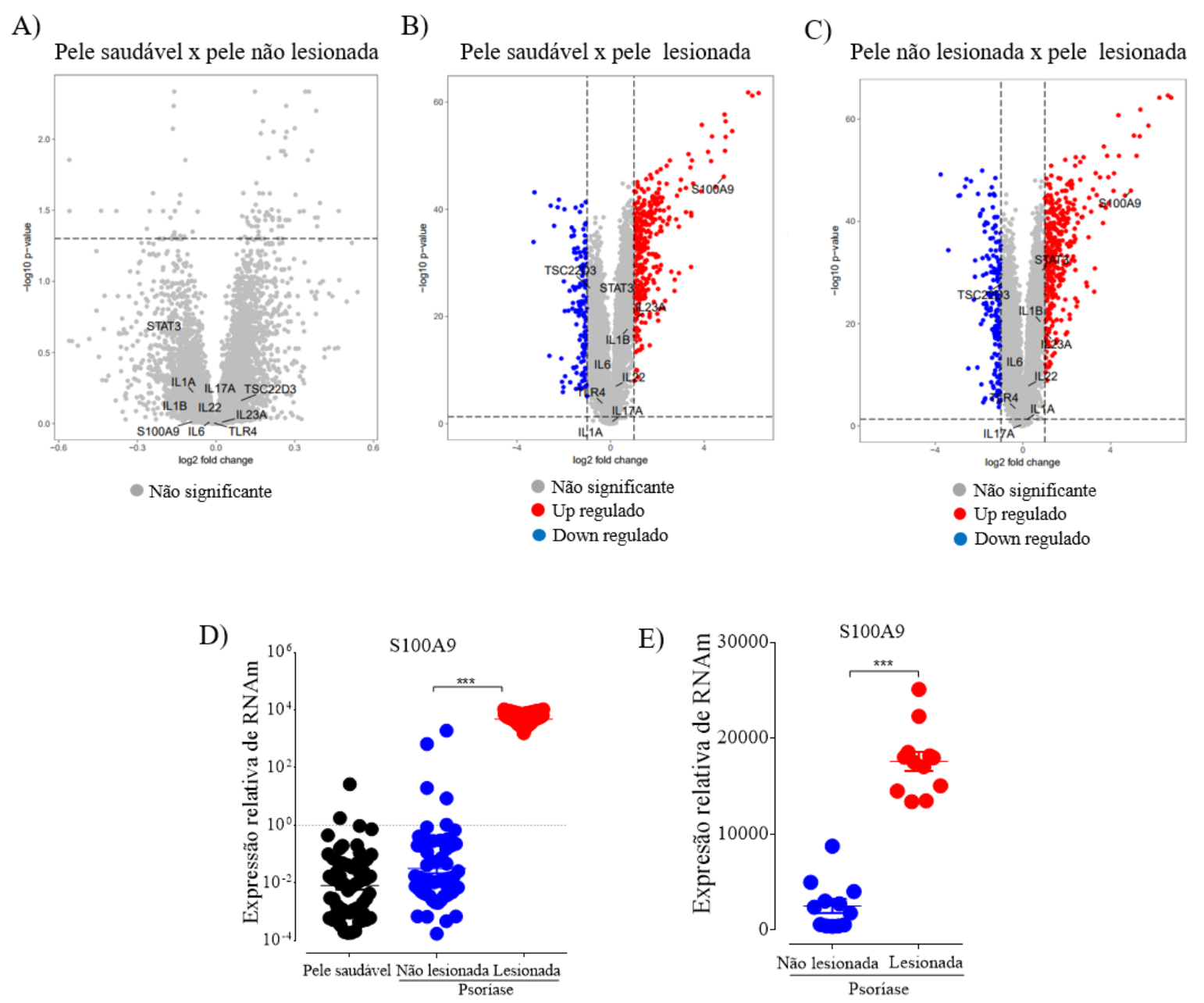

Figura 1: A expressão gênica de S100A9 está aumentada na pele lesionada de pacientes com psoríase. Foram realizadas análises de bioinformática do banco de dados GSE13355, que contém valores de expressão gênica de biópsia de pele de 180 indivíduos (amostra de indivíduos saudáveis, amostra lesionada e não lesionada de pacientes com psoríase vulgar). (A) Foram realizadas análises comparando a expressão gênica entre a pele de indivíduos saudáveis e pele não lesionada de pacientes com psoríase, (B) comparando a pele de indivíduos saudáveis e pele lesionada de indivíduos com psoríase, e (C) pele não lesionada e lesionada de pacientes com psoríase e expressas no volcano plot. (D) Representação dos dados de expressão gênica de S100A9 encontrados no banco de dados GSE13355. (E) Representação dos dados de expressão gênica de S100A9 do banco de dados GSE 14905, que contém valores de expressão gênica de biópsia de pele de 83 indivíduos (amostra lesionada e não lesionada de pacientes com psoríase vulgar). Os gráficos representam a média \pm SEM. $* * * \mathrm{P}<0.05$ indica diferença estatisticamente significante entre pele lesionada e não lesionada de indivíduos com psoríase.

Sabendo que existem várias moléculas com funções bem estabelecidas no desenvolvimento da psoríase, e que contribuem diretamente para o desenvolvimento e manutenção da psoríase, fomos avaliar se algumas dessas moléculas estariam correlacionados positivamente com a expressão de S100A9 na pele lesionada de pacientes com psoríase. Para isso, utilizamos o banco 
de dados GSE 13355, disponível online, que contém valores de expressão gênica da pele de 180 amostras, entre elas, pele de indivíduos saudáveis, pele lesionada e não lesionada de pacientes com psoríase. Podemos observar que a expressão de S100A9 está correlacionada positivamente com a expressão de outros genes já previamente descritos, associados com o desenvolvimento e manutenção da psoríase, como KRT17, LCN2, IL22, IL36G, STAT3 e IL-23 (FIGURA2).

A)

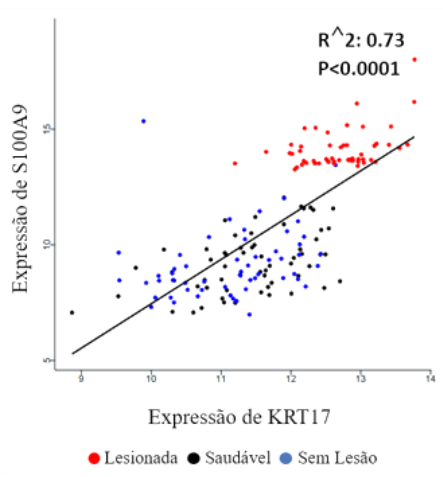

D)

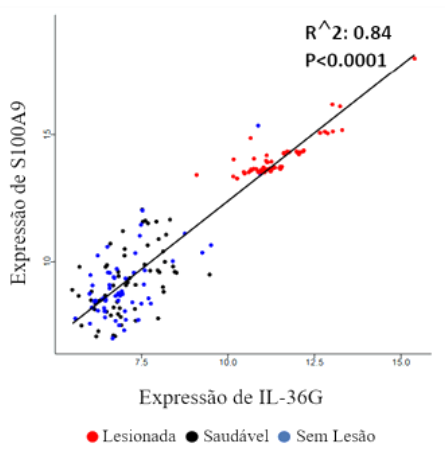

B)

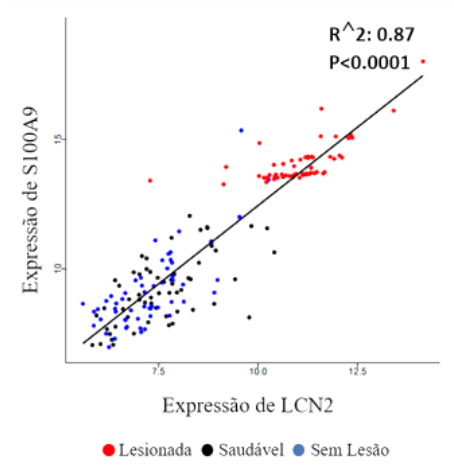

E)

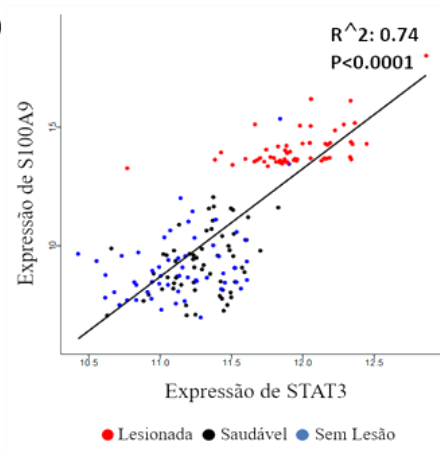

C)

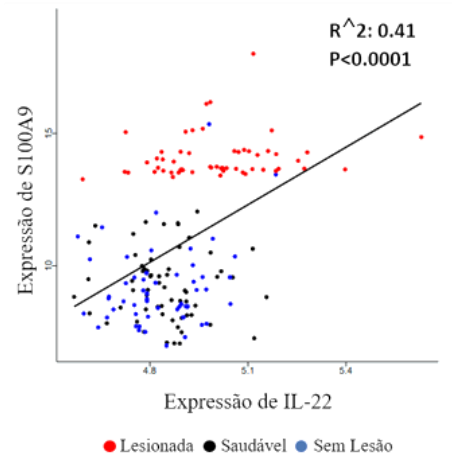

F)

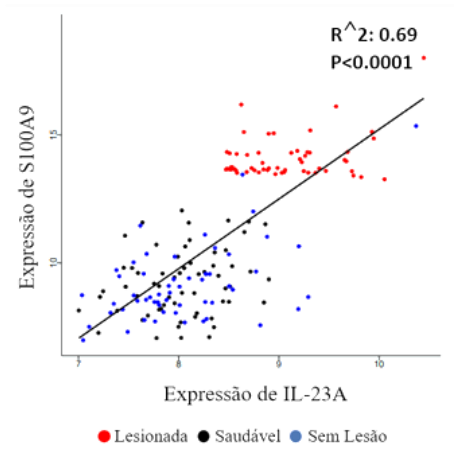

Figura 2: A expressão gênica de S100A9 está correlacionada positivamente com genes associados a psoríase na pele lesionada de pacientes com psoríase. Foram realizadas análises de bioinformática do banco de dados GSE 13355, que contém valores de expressão gênica de pele de 180 indivíduos (Pele de indivíduos saudáveis, pele lesionada e não lesionada de pacientes com psoríase). (A) Foram realizadas análises de correlação da expressão gênica de s100a9 entre krt17, lcn2, il-22, il-36g, stat3 e il-23 entre a pele de indivíduos saudáveis e pele lesionada e não lesionada de pacientes com psoríase. Para as análises de correlação usou-se o teste estatístico de Spearman.

Corroborando os dados, observamos que existe um aumento de S100A9 na pele lesionada de pacientes com psoríase por western Blotting (FIGURA 3A) e imunofluorescência 
(FIGURA 3B), em comparação com a pele não lesionada desses mesmos pacientes. $\mathrm{O}$ aumento de S100A9 está confinado principalmente na epiderme e está co-localizado com outras proteínas marcacadoras de ativação e proliferação de queratinócitos (FIGURA 3C).

A)

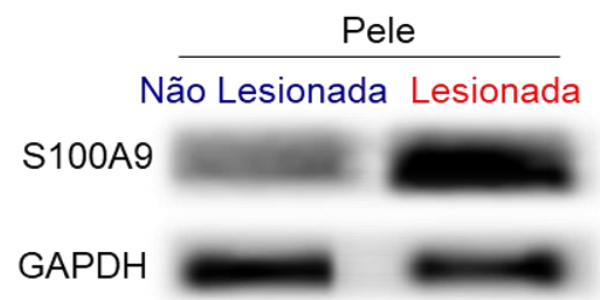

B)

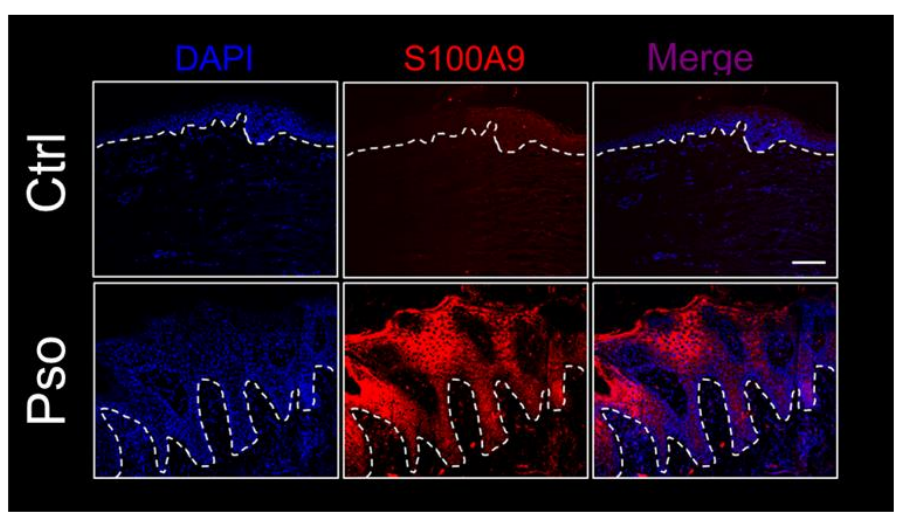

C)

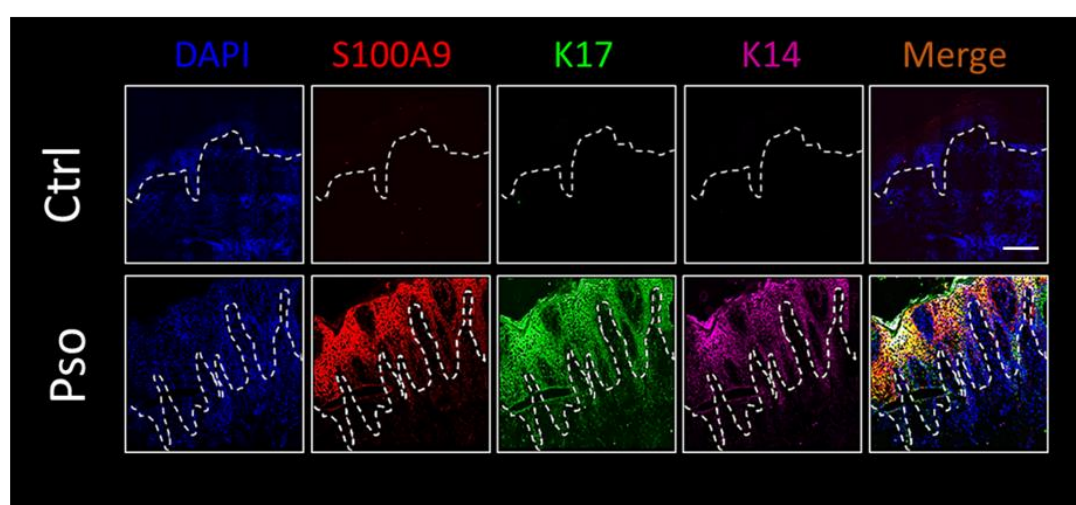

Figura 3: A expressão proteica de S100A9 está aumentada e localizada principalmente na epiderme na pele lesionada de pacientes com psoríase. (A) A expressão proteica de S100A9 na pele lesionada e não lesionada de pacientes com psoríase foi avaliada por western blotting $(n=1)$ e (B) Imunofluorescência $(n=1)$. (C) Por imunofluorescência foi analisada a expressão de K14 e K17, além da expressão de s100a9, na pele lesionada e não lesionada de pacientes com psoríase $(\mathrm{n}=1)$. Dados representativos de um experimento. 


\subsection{AUMENTO DA EXPRESSÃO DE S100A9 NO MODELO DE PSORÍASE EXPERIMENTAL}

A fim de entender melhor como estava a expressão de S100A9 no desenvolvimento da psoríase, utilizamos o modelo de psoríase experimental, induzido por IMQ. Nossos dados mostram que além do aumento da expressão gênica de S100A9 na pele lesionada de pacientes com psoríase (FIGURA1B e C), a expressão gênica de s100a9 também está aumentada na pele de camundongos após aplicação tópica de IMQ (FIGURA 4). Além disso, outros genes relacionados com proliferação de queratinócitos, desenvolvimento e manutenção da psoríase, como Lcn2, S100a8, K17, Il17, Il22, Il23, Il36g, Il6 também estão regulados positivamente na pele de camundongos após aplicação tópica de IMQ (FIGURA 4).

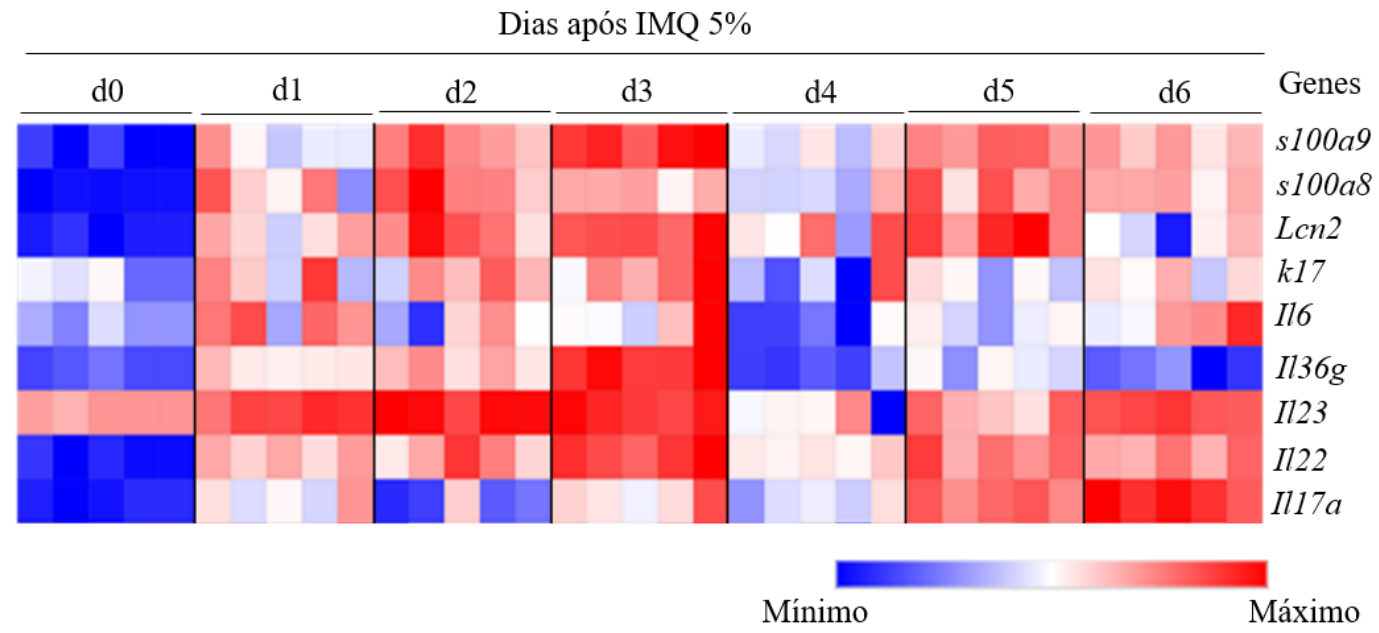

Figura 4: A expressão de S100A9 e outros genes relacionados com proliferação de queratinócitos e respostas pró-inflamatórias estão aumentados na pele após aplicação tópica de IMQ no dorso de camundongos WT. (A) A expressão relativa dos foi determinada por qPCR, da pele de camundongos WT $(\mathrm{n}=5)$, do dia 0 ao dia 6 , após aplicação tópica de IMQ no dorso dos animais. A diferença entre os dias foi considerada estatisticamente diferente do dia 0 (WT naive) quando o $\mathrm{P}>0.05$. Dados representativos de um experimento.

Assim como na pele lesionada de pacientes com psoríase, observamos que existe um aumento de S100A9 após aplicação tópica de IMQ, representado por western blotting e 
imunofluorescência, (FIGURA 5). O aumento de S100A9 observado na pele, após aplicação de IMQ, inicia no dia segundo dia (Dados não mostrados) e permanece aumentada nos dias seguintes até o sexto dia (FIGURA 5A). Esse aumento de S100A9 está confinado principalmente na epiderme e co-localizada com queratina 17 (K17), um marcador de proliferação de queratinócitos (LEIGH, 1995) (FIGURA 5B).

A)

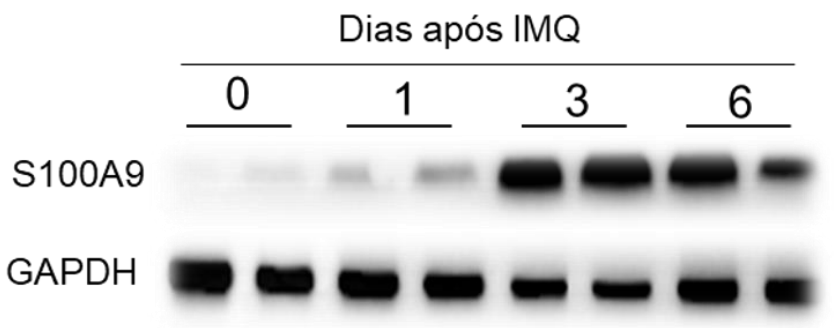

B)

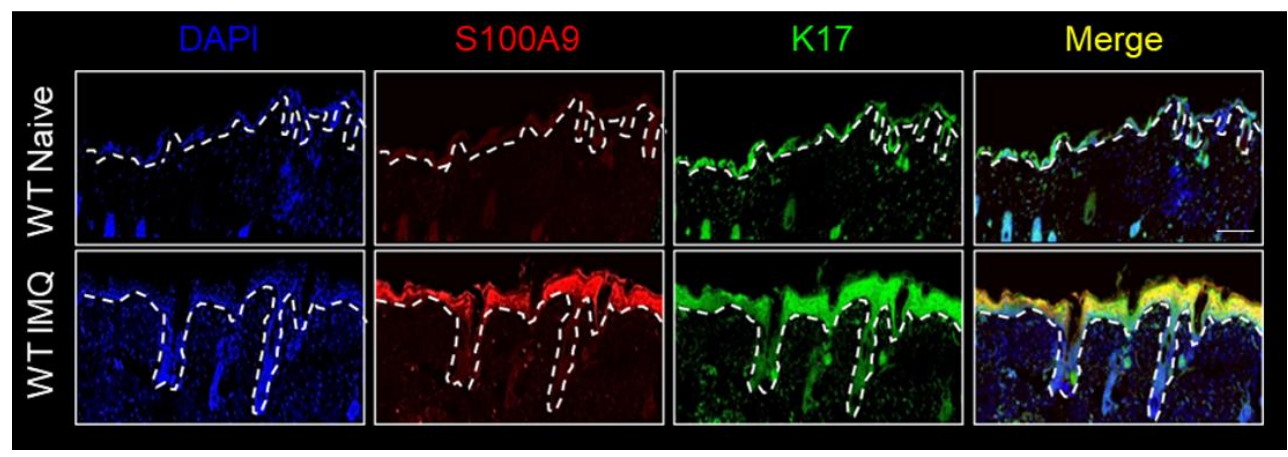

Figura 5: A expressão proteica de S100A9 está aumentada e co-localizada principalmente na epiderme na pele de camundongos WT após aplicação tópica de IMQ. (A) Após aplicação diária de IMQ no dorso de camundongos WT $(\mathrm{n}=5)$, foi avaliado do dia 0 ao dia 6 a expressão de S100A9 na pele por western blotting. A imagem é representativa dos dias $0,1,3$ e 6. (B) Após aplicação diária de IMQ no dorso de camundongos WT $(n=5)$, foi avaliado no dia 6 a expressão de S100A9 e queratina 17 na pele, por imunofluorescência. Dados representativos de um experimento.

Além das células epiteliais, células mielóides como células dendríticas também podem produzir S100A9 em condições de ativação. A fim de avaliar se essas células poderiam estar expressando S100A9, avaliamos por qPCR a expressão de S100a9 nos linfonodos 
drenantes da pele. Observamos que assim como na pele (FIGURA 4), a expressão gênica de S100a9 está aumentada nos linfonodos drenantes da pele, após aplicação tópica de IMQ na pele de camundongos Além disso, existe um aumento na expressão de genes pró-inflamatórios, relacionados com desenvolvimento e manutenção da psoríase, como, $S 100 a 8, I L-1 \beta, I L-6, I L$ 23, IL-22 e $I L-17 a$ também estão regulados positivamente nos linfonodos drenantes da pele após aplicação tópica de IMQ em camundongos (FIGURA 6).

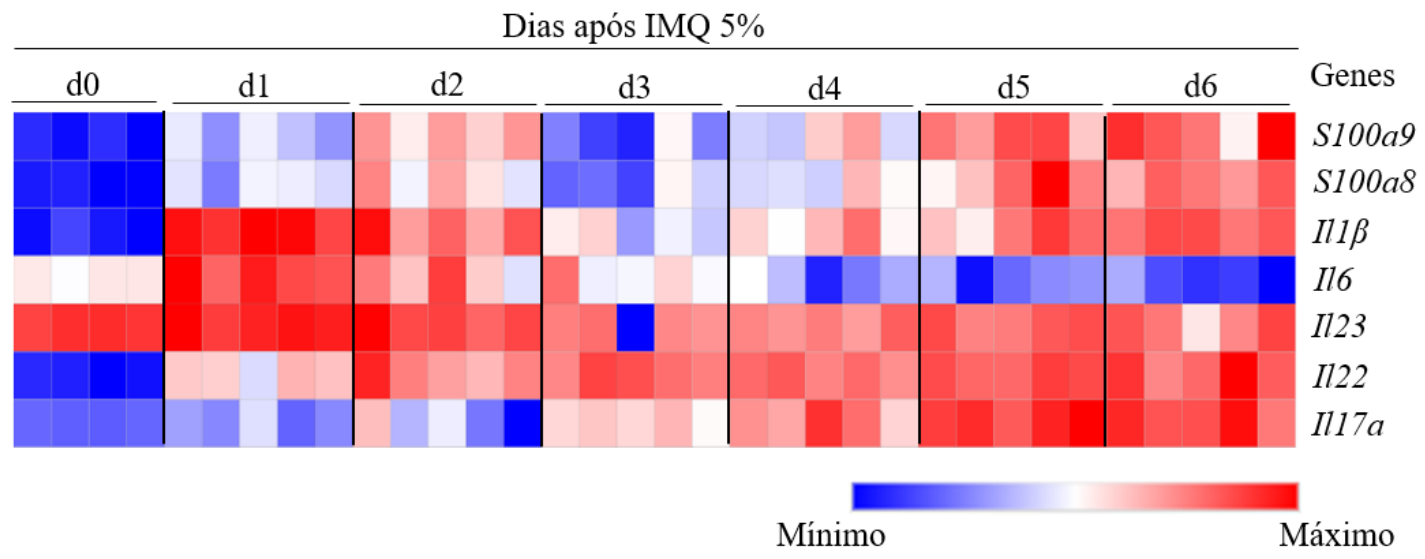

Figura 6: A expressão de S100A9 e outros genes relacionados com respostas próinflamatórias estão aumentados no linfonodo após aplicação tópica de IMQ no dorso de camundongos WT. (A) A expressão relativa dos genes foi determinada por qPCR, dos linfonodos drenantes da pele de camundongos WT $(\mathrm{n}=5)$, do dia 0 ao dia 6 , após aplicação tópica de IMQ no dorso dos animais. A diferença entre os dias foi considerada estatisticamente diferente do dia 0 (WT naive) quando o $\mathrm{P}>0.05$. Dados representativos de um experimento.

Assim como na pele de camundongos WT após aplicação de IMQ, nossos dados mostram que existe um aumento de S100A9 nos linfonodos drenantes da pele, demosntrados por western blotting e imunofluorescência, (FIGURA 7). Para a nossa surpresa, o aumento de S100A9 nos linfonodos, após aplicação de IMQ, inicia no dia 1, um dia antes da pele, e permanece aumentado nos dias seguintes até o dia 6 (FIGURA 7A). Sabendo que as DC's podem produzir S100A9 e que essas células constituem uma boa parte dos linfonodos, fomos investigar se esse aumento de S100A9 tinha alguma relação com essas células. Nossos dados 
de imunofluorescência demonstram que existe uma co-localização entre S100A9 e células CD11c nos linfonodos drenantes da pele, 3 dias após aplicação tópica de IMQ em camundongos WT. No entanto, outras células dos linfonodos, como os linfócitos B, marcados com anti-B220 não mostraram nenhuma co-localização com S100A9 (FIGURA 7 C e D).

A)

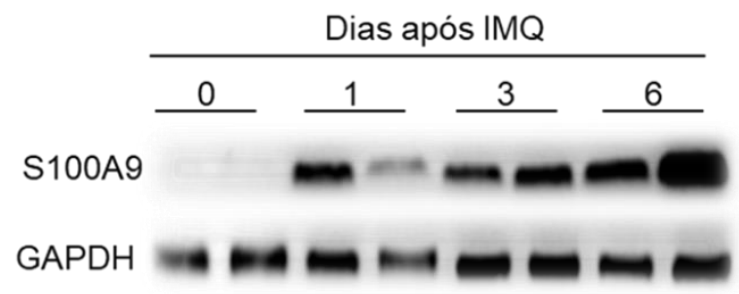

B)

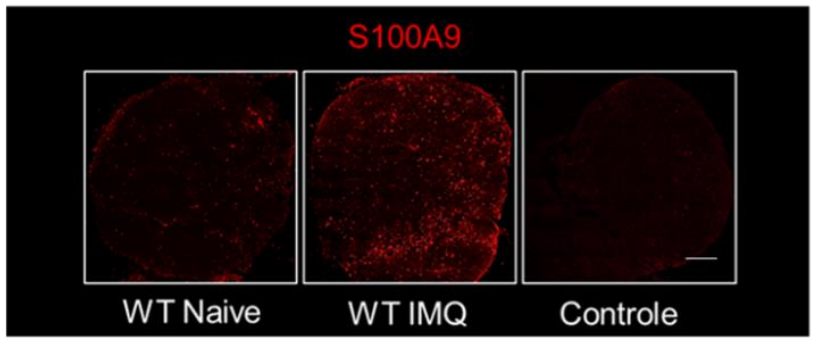

C)

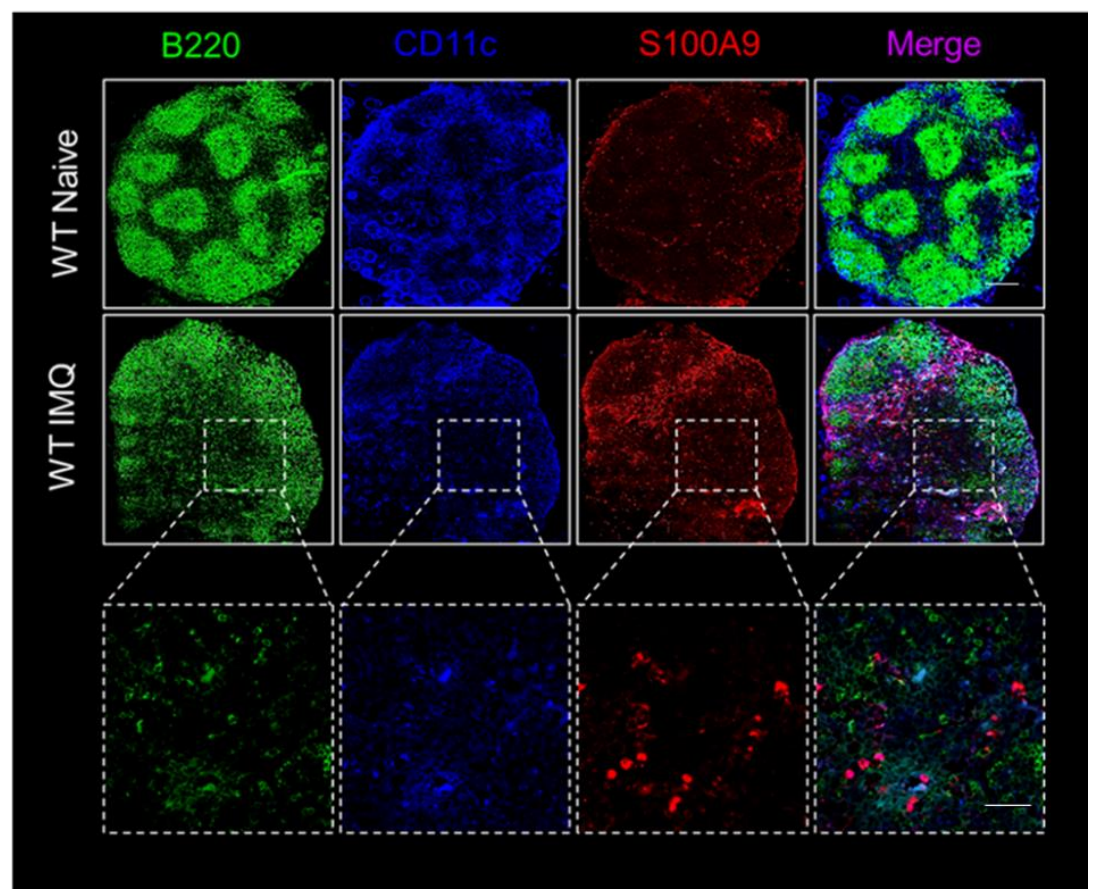

Figura 7: A expressão proteica de S100A9 está aumentada e co-localizada com células CD11c+ nos linfonodos drenantes da pele de camundongos WT após aplicação tópica de IMQ. (A) Após aplicação diária de IMQ no dorso de camundongos WT (n=5), foi avaliado nos linfonodos drenantes da pele, do dia 0 ao dia 6 , a expressão de S100A9 por western blotting. A imagem é representativa dos dias $0,1,3$ e 6 . (B) Por imunofluorescência, foi avaliada a expressão de S100A9 em animais WT sem aplicação (wt naive) e após aplicação de IMQ (wt imq) no dorso. O linfonodo controle representa a marcação somente com o anticorpo 
secundário. (C) Por imunofluorescência foi avaliada a expressão de S100A9, B220 e CD11c no aumento de 10x (D) e no aumento 40x. Dados representativos de um experimento.

\subsection{AUSÊNCIA OU INIBIÇÃO FARMACOLÓGICA DE S100A9 DIMINUEM A INFLAMAÇÃO E ESPESSAMENTO DA EPIDERME NO MODELO DE PSORÍASE EXPERIMENTAL}

Para avaliar a importância biológica de S100A9 in vivo, utilizamos camundongos geneticamente deficientes para S100A9 (S100A9-/-). Nossos resultados demonstram que camundongos S100A9-/- apresentaram menor eritema da pele, em comparação com os camundongos WT (dia 4) após aplicação tópica de IMQ (FIGURA 8A). Além disso a deficiencia de S100A9 reduziu o espessamento da pele, do dia 4 ao dia 6 (FIGURA 8B), reduziu o espessamento da epiderme e acantose, demonstrado por meio de cortes histológicos corados com Hematoxilina e Eosina (HE) (FIGURA 8C), diminuiu a formação de vasos, visto visualmente no dorso dos camundongos (FIGURA 8D), e diminuiu o tamanho e peso do baço (FIGURA 8E), em comparação com camundongos WT, após aplicação diária de IMQ. 
A)

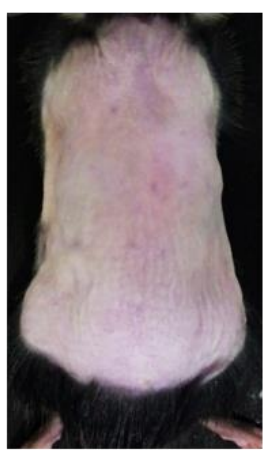

Naive
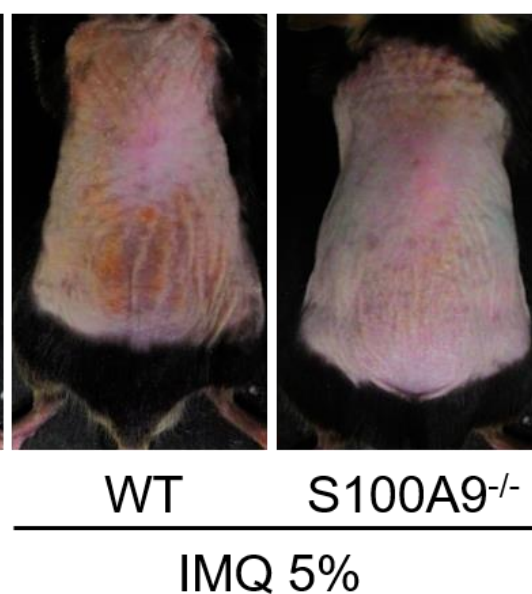

B)
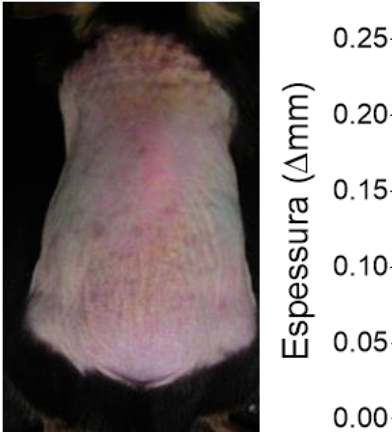

0.00
Waive

S100A9

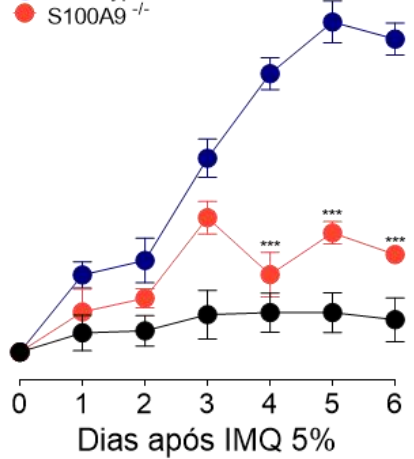

C)
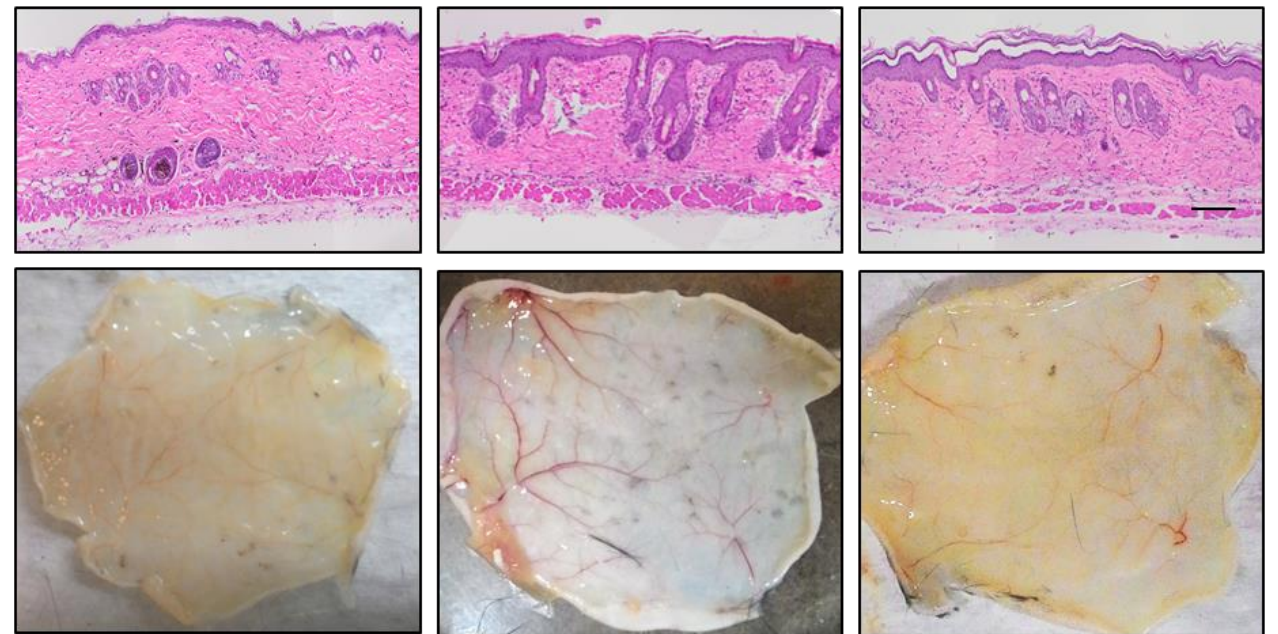

Naive

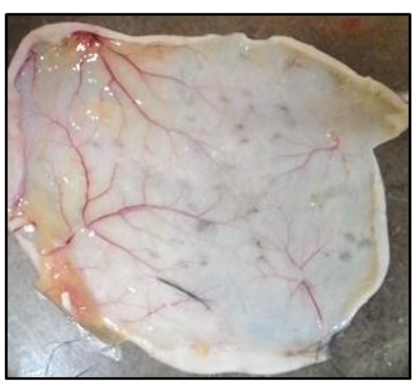

WT

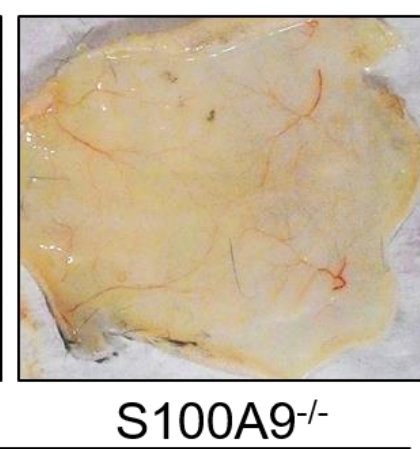

Imiquimod 5\%

D)
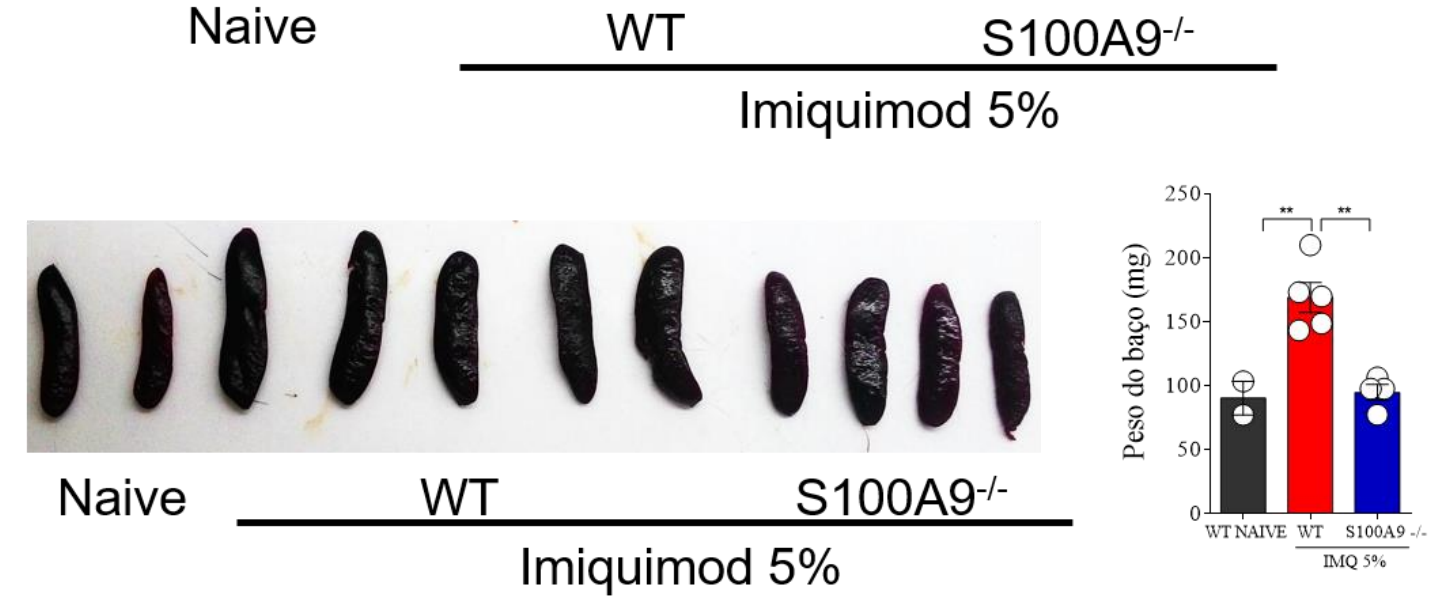

Figura 8: A ausência genética de S100A9 diminui a espessura da epiderme, diminui a formação de vasos e reduz a inflamação após aplicação tópica de IMQ. (A) Foto de 
camundongos WT naive, WT e S100a9 -/- após 4 dias de aplicação de IMQ no dorso $(\mathrm{n}=5)$. (B) Foi avaliado diariamente, do dia 0 ao 6, a espessura da pele de camundongos WT naive, WT e S100a9 -/- após aplicação de IMQ no dorso $(n=5)$. (C) Foi avaliado no dia 6, por coloração com HE, a espessura da pele, (D) a formação visual de vasos no dorso e o (E) peso do baço de camundongos WT naive, WT e S100a9 -/- após aplicação diária de IMQ no dorso. Os grupos foram considerados estatisticamente diferentes do grupo WT IMQ quando o P>0,05. Dados representativos de um experimento.

Para corroborar os dados anteriores, utilizamos um composto quelante de S100A9, o paquinimode (PAQ), que impede a ligação de S100A9 nos seus receptores. Os animais foram tratados com uma dose de $10 \mathrm{mg} / \mathrm{kg}$, via oral. O tratamento foi feito um dia antes e diariamentedurante os 6 dias da aplicação IMQ. Nossos resultados demonstram que camundongos WT tratados com PAQ apresentaram menor eritema, em comparação com os camundongos WT (dia 4) sem tratamento, após aplicação tópica de IMQ (FIGURA 9A). Além disso, a inibição de S100A9 reduziu o espessamento da pele, do dia 4 ao dia 6 (FIGURA 9B), reduziu o espessamento da epiderme e acantose, demonstrado por meio de cortes histológicos corados com Hematoxilina e Eosina (HE) (FIGURA 9C), diminuiu a formação de vasos, visto visualmente no dorso dos camundongos (FIGURA 9D), e diminuiu o tamanho e peso do baço (FIGURA 9E), em comparação com camundongos WT sem tratamento farmacológico com PAQ, após aplicação diária de IMQ. 
A)

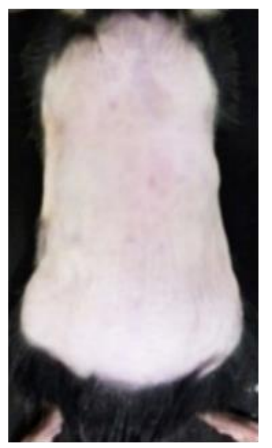

Naive
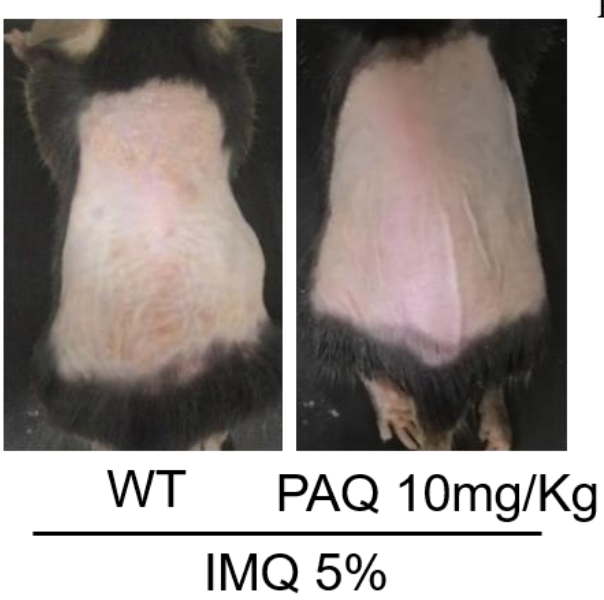

B)

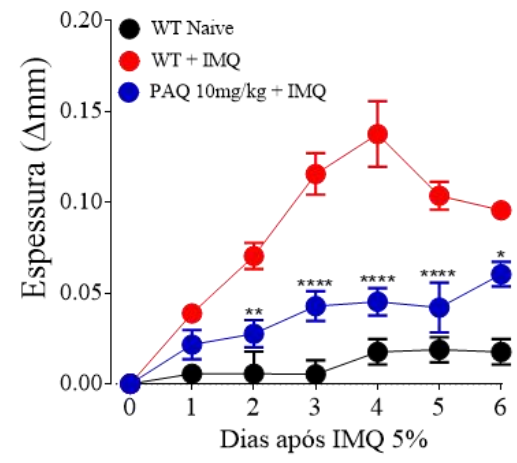

C)

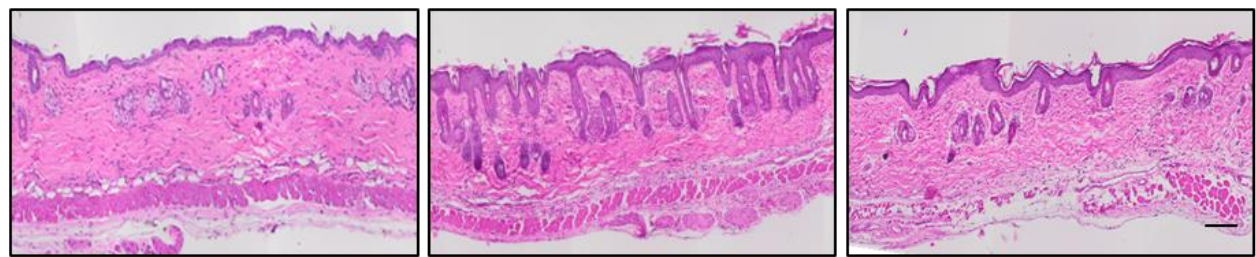

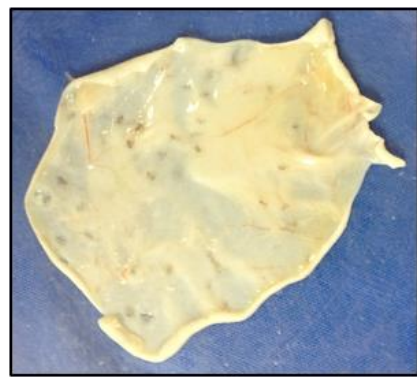

Naive

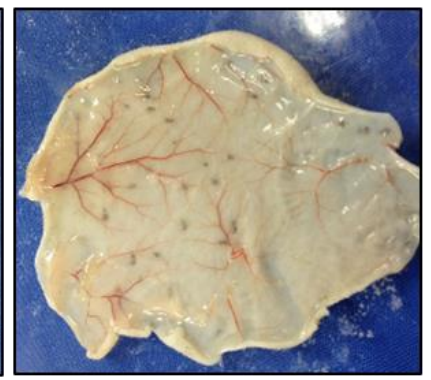

WT

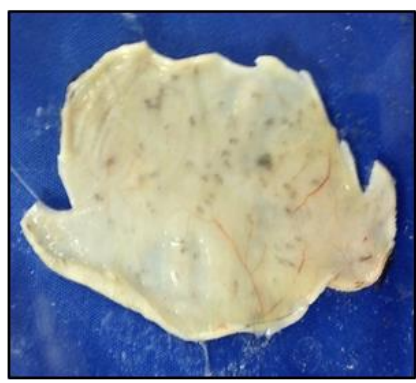

$\mathrm{PAQ} 10 \mathrm{mg} / \mathrm{kg}$

Imiquimod 5\%

E)
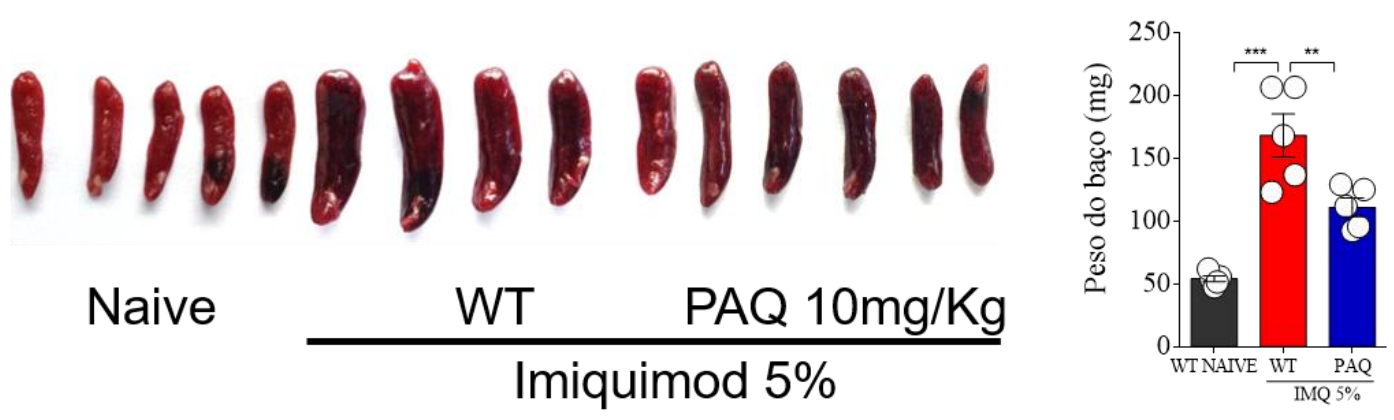

Figura 9: A inibição farmacológica de S100A9 diminui a espessura da epiderme, diminui a formação de vasos e reduz a inflamação após aplicação tópica de IMQ (A) Foto 
de camundongos WT naive e WT após 4 dias de aplicação de IMQ no dorso com ou sem tratamento farmacológico com PAQ na dose de $10 \mathrm{mg} / \mathrm{kg}$, por via oral $(\mathrm{n}=5)$. (B) Foi avaliado diariamente, do dia 0 ao 6, a espessura da pele de camundongos WT naive e WT após aplicação de IMQ no dorso com ou sem tratamento farmacológico com PAQ na dose de $10 \mathrm{mg} / \mathrm{kg}$, por via oral $(n=5)$. (C) Foi avaliado no dia 6, por coloração com HE, a espessura da pele, (D) a formação visual de vasos e o (E) peso do baço de camundongos WT naive e WT, após aplicação diária de IMQ com ou sem tratamento farmacológico com PAQ na dose de $10 \mathrm{mg} / \mathrm{kg}$, por via oral. Os grupos foram considerados estatisticamente diferentes do grupo WT IMQ quando o $\mathrm{P}>0,05$. Dados representativos de um experimento.

\subsection{AUSÊNCIA GENÉTICA OU INIBIÇÃO FARMACOLÓGICA DE S100A9 DIMINUEM A FREQUÊNCIA DE LINFÓCITOS TCR $\gamma \delta$ IL-17+, MAS NÃO ALTERAM A FREQUÊNCIA DE LINFÓCITOS TCD4 IL7+ E LTCD4 FOXP3+}

A psoríase é uma doença dependente de células Th17 e TCR $\gamma \delta$, produtoras de IL-17 e IL22, que ativam e induzem uma proliferação exacerbada de queratinócitos, que produzem mediadores pró-inflamatórios e contribuem para o desenvolvimento e manutenção da doença (DI CESARE, 2009; WEAVER, 2007; BETTELLI, 2007; KASTELEIN, 2007). A ausência ou inibição de S100A9 diminui o espessamento da epiderme e outros parâmetros inflamatórios (FIGURA 8 e 9). Assim nossa hipótese foi de que S100A9 poderia diminuir a produção de IL17 pelas células Th17 e TCR $\gamma \delta$, e levar a redução do escore e inflamação observado na psoríase. Por citometria de fluxo, observamos que tanto a ausência genética ou inibição farmacológica de S100A9 diminuíram a frequência de células TCR $\gamma \delta$ IL-17+ (FIGURA 10A e 11A), mas não influenciou na frequência de células Th17, nos linfonodos drenantes da pele, 6 dias após aplicação tópica de IMQ (FIGURA 10B e 11B). Além dessas células envolvidas na indução da inflamação, existem outras células responsáveis pela regulação da resposta inflamatória, como as células T reguladoras, que cumprem um papel central na tolerância periférica, evitando o desenvolvimento de respostas inflamatórias exacerbadas e desenvolvimento de doenças autoimunes. Como a ausência ou inibição de S100A9 diminui o espessamento da epiderme e outros parâmetros inflamatórios (FIGURA 8 e 9), nós hipotetizamos que essas células poderiam 
estar alterando a frequência de linfócitos T reguladores, no entanto nossos resultados mostram que tanto a ausência genética ou inibição farmacológica não alteram a frequência dessas células TCD4 Foxp3, nos linfonodos drenantes da pele, 6 dias após de aplicação tópica de IMQ (FIGURA 10C e 11C)
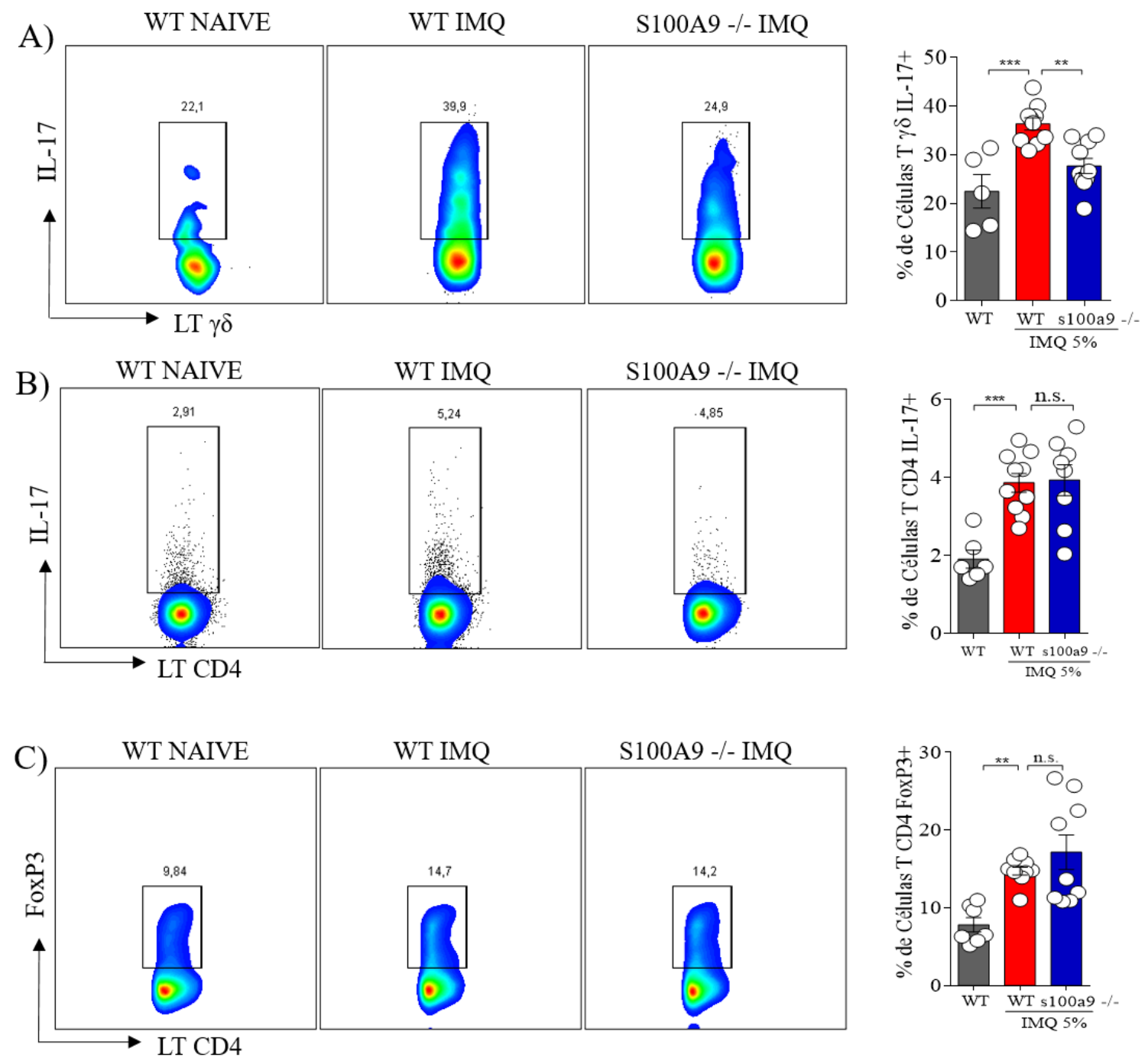

Figura 10: A ausência genética de S100A9 diminui a frequência de linfócitos TCR $\gamma \delta$ IL17+ nos linfonodos drenantes da pele, mas não altera a frequência de Linfócitos TCD4 IL17+ e Linfócitos TCD4 FoxP3+ após aplicação tópica de IMQ. (A) Por citometria de fluxo, foi feita a quantificação da frequência populacional de linfócitos TCR $\gamma \delta$ IL-17+, (B) Linfócitos TCD4 IL-17+ e (C) Linfócitos TCD4 FoxP3+ de camundongos WT naive, WT e S100a9 -/dos linfonodos drenantes da pele, após 6 dias de aplicação tópica de imiquimode no dorso. Os grupos foram considerados estatisticamente diferentes do grupo WT IMQ quando o P>0,05. Dados representativos de dois experimentos independentes. 

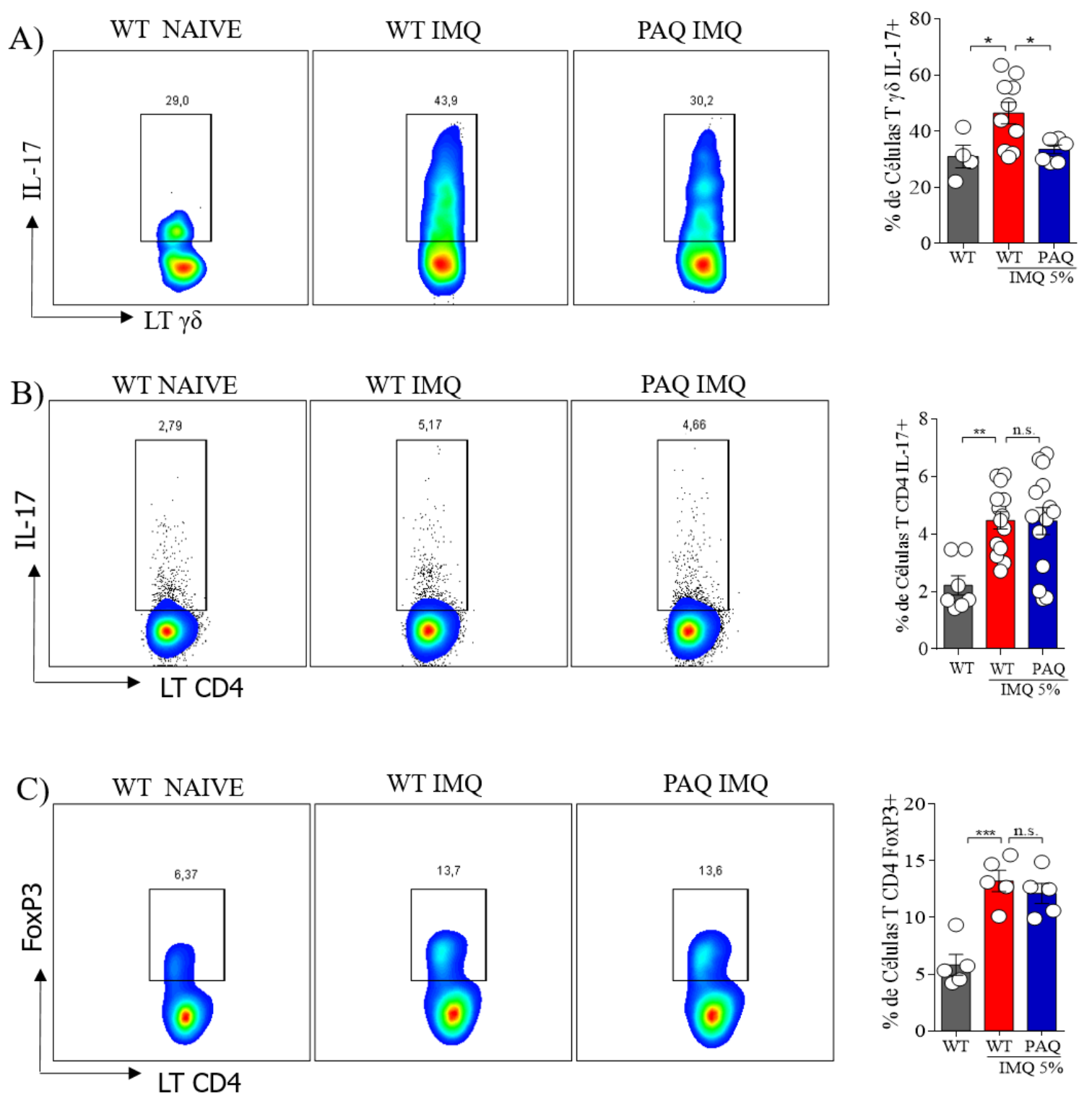

Figura 11: A Inibição Farmacológica de S100A9 diminui a frequência de Linfócitos TCR $\gamma \delta$ IL-17+ nos linfonodos drenantes da pele, mas não altera a frequência de Linfócitos TCD4 IL-17+ e Linfócitos TCD4 FoxP3+ após aplicação tópica de IMQ. (A) Por citometria de fluxo, foi feita a quantificação da frequência populacional de linfócitos TCR $\gamma \delta$ IL-17+, (B) Linfócitos T CD4 IL-17+ e (C) Linfócitos TCD4 FoxP3+ de camundongos WT naive, WT e S100a9 -/- dos linfonodos drenantes da pele, após 6 dias de aplicação tópica de imiquimode no dorso. Os grupos foram considerados estatisticamente diferentes do grupo WT IMQ quando o $\mathrm{P}>0,05$. Dados respresentativos de dois experimentos independentes. 


\subsection{CÉlulAS MiELÓIDES E CÉlULAS EPITELIAIS PRODUZEM S100A9, E AMBAS CONTRIBUEM PARA O AUMENTO DO ESPESSAMENTO DA EPIDERME}

Nossos resultados mostram que camundongos S100A9-/- apresentaram menor vermelhidão e menor descamação da pele, em comparação com os camundongos WT (dia 4), após aplicação tópica de IMQ na orelha (FIGURA 12A). Além disso a ausência genética de S100A9 reduziu o espessamento da pele, do dia 3 ao dia 6 (FIGURA 12B). Para corroborar os nossos dados na orelha, utilizamos o tratamento farmacológico com PAQ. Os animais foram tratados com uma dose de $10 \mathrm{mg} / \mathrm{kg}$, via oral. O tratamento foi feito um dia antes, durante 6 dias da aplicação diária IMQ na orelha. Nossos resultados mostram que camundongos WT tratados com PAQ apresentaram menor vermelhidão da pele e menor descamação, em comparação com os camundongos WT (dia 4) sem tratamento, após aplicação tópica de IMQ na orelha (FIGURA 12C). Além disso, a inibição farmacológica de S100A9 reduziu o espessamento da pele, do dia 4 ao dia 6 (FIGURA 12D). 
A)

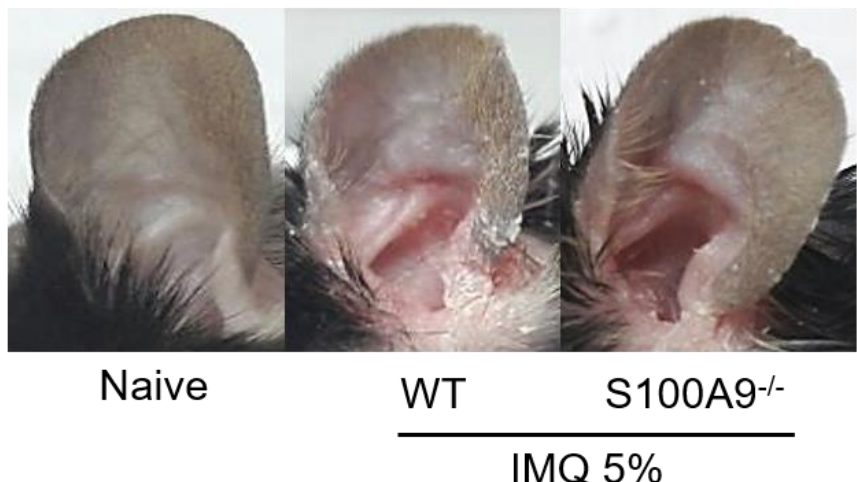

C)

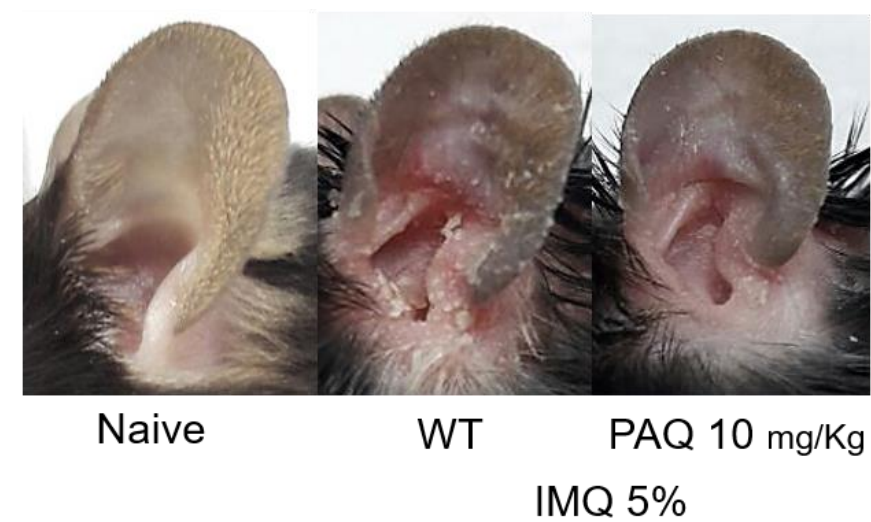

B)

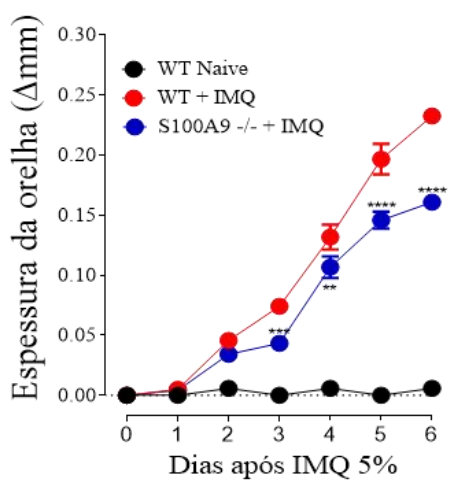

D)

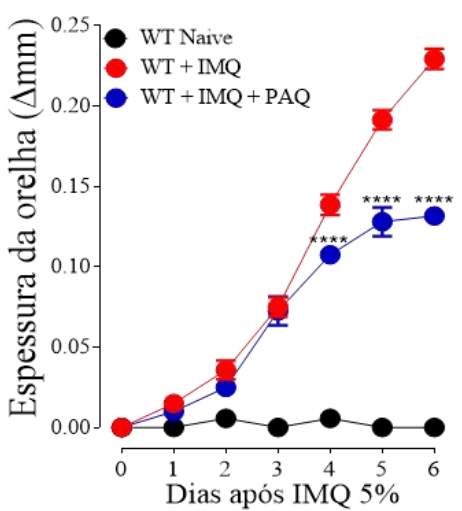

Figura 12: A ausência genética de S100A9 ou inibição farmacológica diminui a espessura da epiderme e reduz a inflamação após aplicação tópica de IMQ na orelha. (A) Foto de camundongos WT naive, WT e S100a9 -/- após 4 dias de aplicação de IMQ na orelha $(\mathrm{n}=5)$. (B) Foi avaliado diariamente, do dia 0 ao 6, a espessura da pele de camundongos WT naive, WT e S100a9 -/- após aplicação de IMQ no dorso (n=5). (C) Foto de camundongos WT naive e WT após 4 dias de aplicação de IMQ no dorso com ou sem tratamento farmacológico com PAQ na dose de $10 \mathrm{mg} / \mathrm{kg}$, por via oral (n=5). (D) Foi avaliado diariamente, do dia 0 ao 6 , a espessura da pele de camundongos WT naive e WT após aplicação de IMQ no dorso com ou sem tratamento farmacológico com PAQ na dose de $10 \mathrm{mg} / \mathrm{kg}$, por via oral $(\mathrm{n}=5)$.

Sabendo que S100A9 pode ser produzida por células epiteliais e células mielóides, nossa próxima pergunta foi tentar entender quais desses subtipos de células produtoras de S100A9 seria mais importante para o desenvolvimento da psoríase experimental. Para isso geramos animais quimeras, onde camundongos WT receberam medula S100A9-/- (WT $\rightarrow$ S100A9) e camundongos S100A9-/- receberam medula WT $($ S100A9 $\rightarrow$ WT), gerando assim animais 
deficientes para S100A9 somente nas células mielóides e nos queratinócitos, respectivamente (FIGURA 9A). Primeiramente, nossos dados mais uma vez confirmam que a ausência genética total de S100A9 é crítica para o desenvolvimento da psoríase, diminuindo o espessamento da epiderme e frequência de TCR $\gamma \delta$ IL-17+, quando comparamos os grupo WT que recebeu medula WT com o grupo S100A9-/- que recebeu medula S100A9-/-, após aplicação tópica de IMQ na orelha (FIGURA 9B,C e D). Além disso, nossos dados mostram que a ausência genética de S100A9 em um desses grupos de células diminui o espessamento da pele (FIGURA 9B), além de diminuir a frequência de TCR $\gamma \delta$ IL-17+ nos linfonodos cervicais (FIGURA 9D), avaliado por citometria de fluxo 6 dias após aplicação de IMQ na orelha, quando comparado com o grupo dos camundongos WT que receberam medula WT. No entanto, pela coloração com HE é visível que a ausência de S100A9 nos queratinócitos compromete ainda mais a espessura da epiderme, quando comparado com o grupo que é deficiente para S100A9 somente nas células mielóides (FIGURA 9C). 
A)

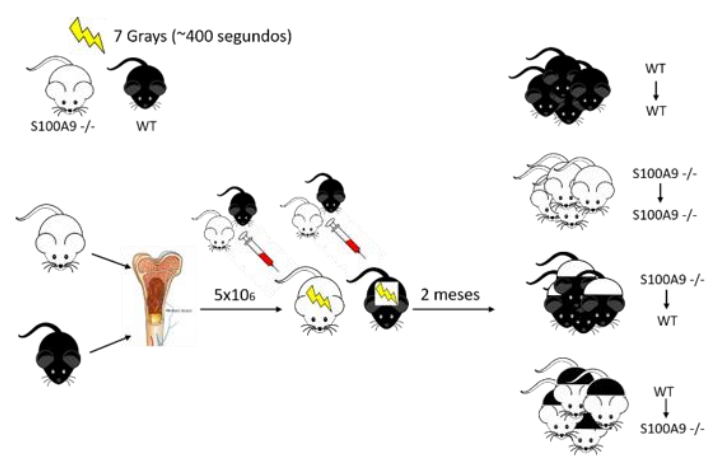

B)

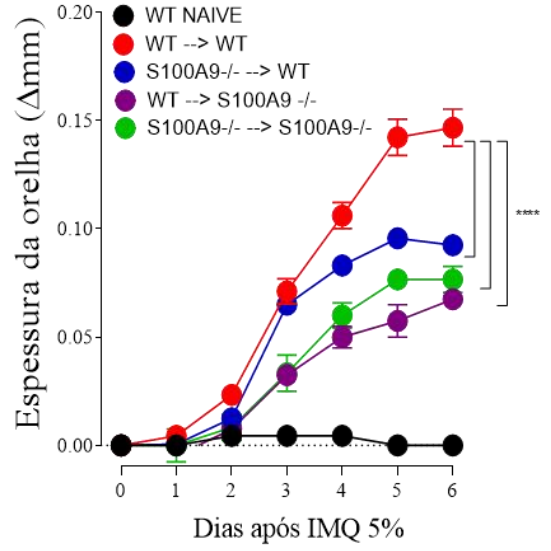

C)

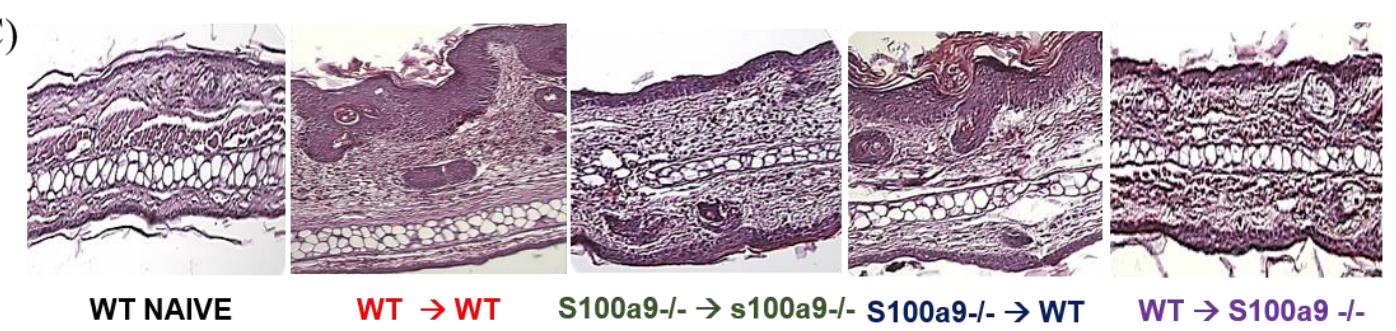

D)
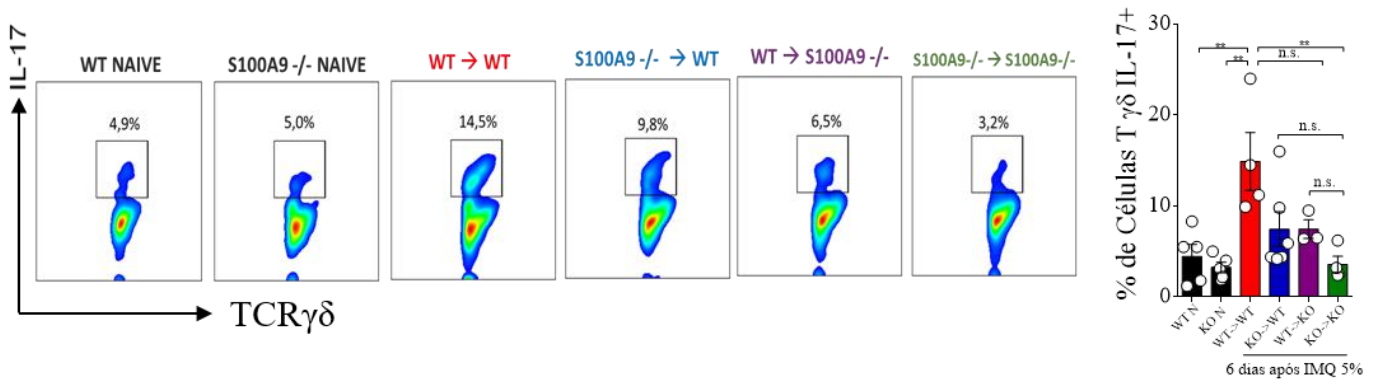

Figura 13: Tanto as células epiteliais quanto as células mielóides, produtoras de s100a9, são importantes para o aumento do espessamento da epiderme, após aplicação de IMQ. (A) Camundongos WT e S100a9 -/- foram irradiados (Grays) e após 24 horas receberam 5x106 células da medula de animais WT ou S100a9 -/-, sendo gerados camundongos WT que receberam medula WT, camundongos S100a9 -/- que receberam medula S100a9 -/-, camundongos WT que receberam medula S100a9 -/- e camundongos S100a9 -/- que receberam medula WT. (B) Foi avaliado diariamente, do dia 0 ao 6 , a espessura da pele dos camundongos quimera, após aplicação de IMQ. (C) A espessura da pele foi avaliada por coloração com HE e (D) por citometria de fluxo, foi feita a quantificação da frequência populacional de linfócitos TCR $\gamma \delta$ IL-17+, no dia 6, após aplicação diária de IMQ na orelha dos camundongos quimera. Os grupos foram considerados estatisticamente diferentes do grupo WT $\rightarrow$ WT IMQ quando o $\mathrm{P}>0,05$. Dados representativos de um experimento.

\subsection{A AUSÊNCIA GENÉTICA DE S100A9 DIMINUI A EXPRESSÃO GÊNICA DE $I L$ - 23 NA PELE APÓS APLICAÇÃO TÓPICA DE IMQ}


Nossos dados até agora mostraram que a ausência genética ou a inibição farmacológica de S100A9 diminuiu alguns parâmetros inflamatórios, como espessamento da pele, tamanho do baço e frequência de linfócitos TCR $\gamma \delta$ IL-17+. No entanto, os mecanismos pelo qual isso estaria acontecendo foi o que nos levou aos próximos experimentos. Os linfócitos TCR $\gamma \delta$ tem um papel crítico no modelo de psoríase após aplicação de IMQ (CAI, 2011; PANTELYUSHIN, 2012), sendo uma das células mais importantes que contribuem para os sinais clássicos da inflamação observado no modelo. Além disso, os linfócitos TCR $\gamma \delta$ IL-17+ tem um papel importante no controle de infecções e em doenças inflamatórias crônicas como a psoríase (PAPOTTO, 2017; CAI, 2011). Essas células expressam receptor para IL-23, que é essencial para a produção de IL-17. Na ausência de IL-23 ou IL-1 $1 \beta$ essas células não produzem IL-17 (CAI, 2011). Portanto, visto que na ausência de S100A9, a frequência de TCR $\gamma \delta$ IL-17+ estava diminuída, nossa hipótese foi de que S100A9 estaria modulando a ativação de células dendríticas, levando estas a produzir mais IL-23, por exemplo, e consequentemente aumentando a frequência de TCR $\gamma \delta$ IL-17+. Para tentar responder a essas perguntas, primeiramente avaliamos a expressão gênica de $I l 23$ na pele, do dia 0 ao dia 6 , após aplicação tópica de IMQ na pele de camundongos WT. Nossos resultados mostram que o dia 2 é o pico da expressão gênica de Il23 na pele, após aplicação de IMQ (FIGURA 14A). Assim, fomos avaliar como estaria a expressão de $I l 23$ e outros genes associados com proliferação de queratinócitos em camundongos S100A9 -/- ou após tratamento farmacológico com PAQ no dia 2, comparando com camundongos WT sem tratamento farmacológico. Nossos dados confirmam uma parte da nossa hipótese, pois na ausência genética ou inibição farmacológica de S100A9 há uma diminuição na expressão gênica de Il23 e outros genes associados com proliferação de queratinócitos como Lcn2 e Il22 nos camundongos S100A9 -/- ou WT tratados com PAQ, 2 dias após aplicação tópica de IMQ (FIGURA 14B). 

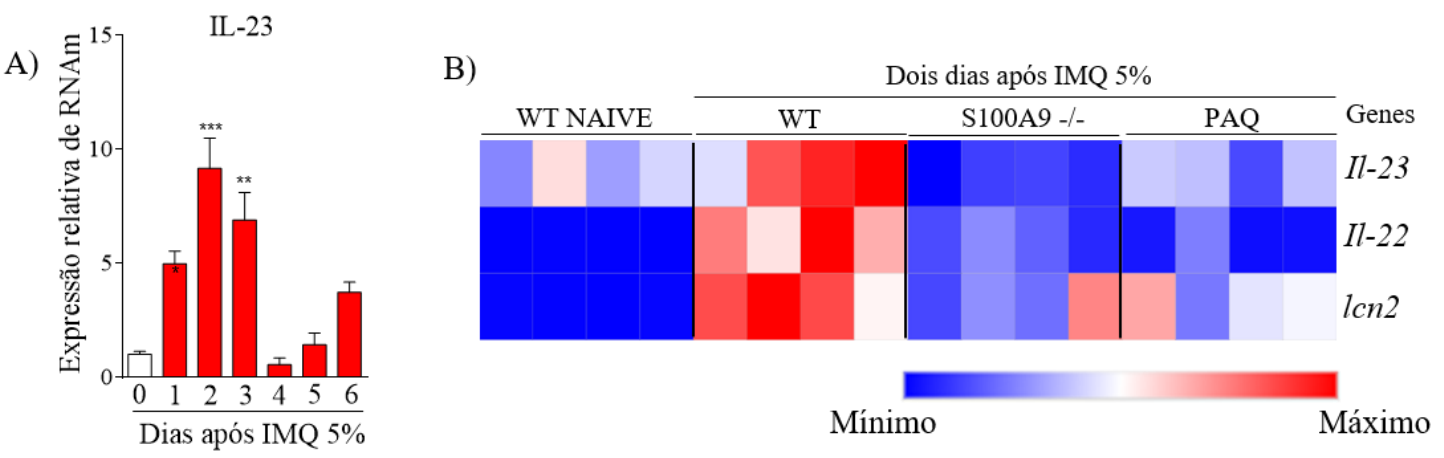

Figura 14: A ausência ou inibição farmacológica de S100A9 diminuem a expressão gênica de expressão de il-23 na pele após aplicação de IMQ 5\%. (A) A expressão relativa do gene il-23 foi determinado por RT-PCR, da pele de camundongos WT $(\mathrm{n}=5)$, do dia 0 ao dia 6 , após aplicação tópica de imiquimode $5 \%$ no dorso dos animais. (B) A expressão relativa do gene $i l$ 23 na pele foi avaliado em camundongos WT naive, S100A9 -/- e WT com ou sem tratamento farmacológico com PAQ na dose de $10 \mathrm{mg} / \mathrm{kg}$, por via oral $(\mathrm{n}=5)$. Os grupos foram considerados estatisticamente diferentes do grupo WT IMQ quando o $\mathrm{P}>0,05$. Dados representativos de um experimento.

\subsection{S100A9 INDUZ A PRODUÇÃO DE IL-6 EM CÉLULAS DENDRÍTICAS DE MANEIRA DEPENDENTE DE TLR4}

Para confirmar se S100A9 estaria modulando diretamente a ativação de células dendríticas, diferenciamos essas células a partir da medula óssea de camundongos WT, com GM-CSF. Após diferenciadas, essas células foram incubadas por 24 horas com diferentes estímulos como LPS, IMQ e S100A9 em diferentes concentrações. A produção de IL-6 foi avaliada por ELISA. Nossos dados mostram que tanto LPS, IMQ e S100A9 induziram a produção de IL-6 em diferentes concentrações (FIGURA 15A, B e C). A combinação de LPS (100ng/ml) mais S100A9 (1ug/ml) aumentou a produção de IL-6, porém sem diferença do grupo somente com LPS na mesma concentração (FIGURA 15D). No entanto, quando adicionamos IMQ na menor concentração $(1 \mathrm{ug} / \mathrm{ml})$ eS100A9 $(1 \mathrm{ug} / \mathrm{ml})$, a produção de IL-6 foi potencializada, quando comparada aos estímulos isolados (FIGURA 15E). Sabe-se que S100A9 pode atuar via os receptores TLR4 e RAGE, ambos expressos em células mielóides. Para o papel do receptor TLR4 nessas células, diferenciamos células dendríticas a partir da medula óssea de camundongos TLR $4^{-/-}$, com GM-CSF. As células foram estimuladas com LPS (500ng/ml), agonista de TLR4, IMQ (10ug/ml), agonista de TLR7 e S100A9, agonista de TLR4 e RAGE. Nossos dados mostram que a produção de IL-6 é dependente de TLR4, uma vez que na ausência desse receptor, essa produção está comprometida (FIGURA 15F). 
A)

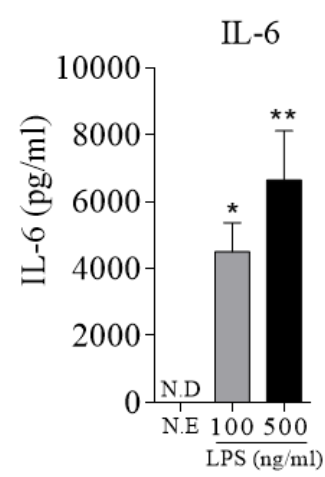

D)

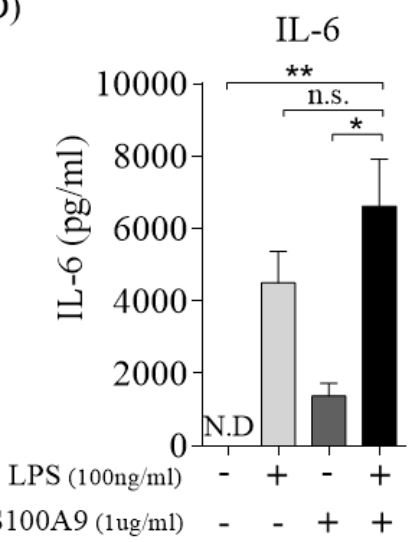

B)

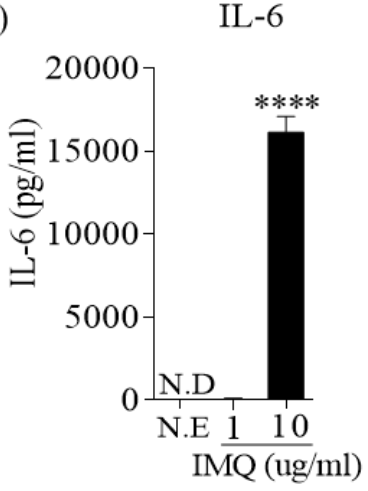

E)

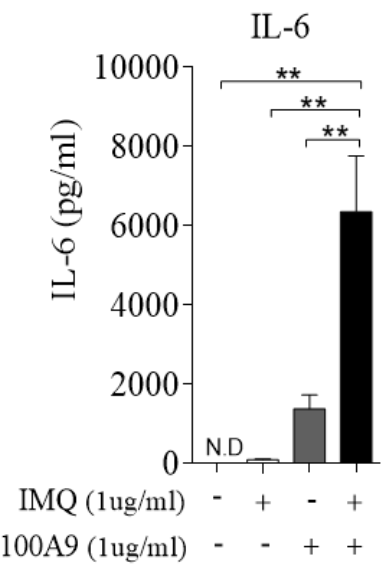

C)

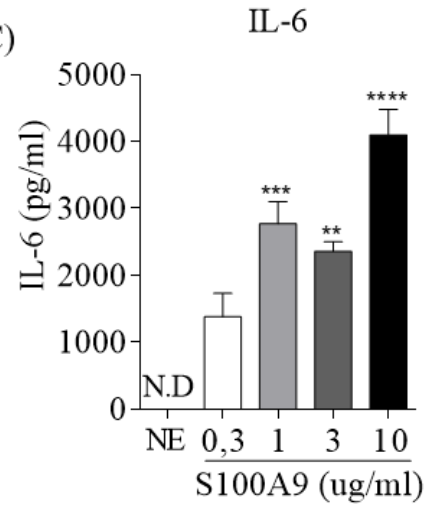

F)

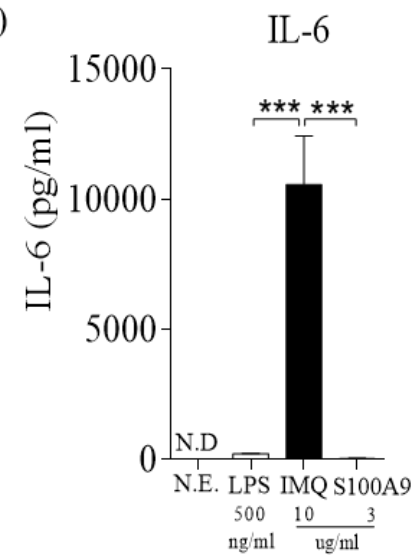

Figura 15: S100A9 induz a produção de IL-6 em células dendríticas derivadas da medula óssea, de maneira dependente de TLR4. Células dendríticas foram geradas da medula de camundongos WT, após estímulo com GM-CSF e após 6 dias foram incubadas com diferentes estímulos. A produção de IL-6 foi quantificada através do sobrenadante das células após estímulo com (A) LPS, (B) IMQ e (C) S100A9 em diferentes concentrações e em combinação de (D) LPS (100ng/ml) mais S100A9 (1ug/ml) e (E) IMQ (1ug/ml) mais S100A9 (1ug/ml). (E) Células dendríticas foram geradas da medula de camundongos tlr4 -/- após estímulo com GMCSF e após 6 dias foram incubadas com LPS (500ng/ml), IMQ (10ug/ml) e S100A9 (3ug/ml). Os resultados foram considerados estatisticamente diferentes quando o $\mathrm{P}>0,05$. Dados representativos de um experimento. 
DISCUSSÃO 


\section{DISCUSSÃO}

As doenças inflamatórias crônicas apresentam várias problemáticas, que incluem tratamento prolongado e nem sempre eficaz, com várias reações adversas, elevados custos ao sistema de saúde e comprometimento direto da qualidade da vida dos pacientes. (DUARTE, 2001; SFIKAKIS, 2005; BRUNER, 2003; KATZ, 2014; SCACCABAROZZI, 2016). Neste sentido, o melhor entendimento dos mecanismos envolvidos no desenvolvimento e manutenção dessas doenças pode levar a descoberta de novos alvos terapêuticos e, assim, alternativas de tratamento mais eficazes.

No presente estudo demonstramos que a expressão de S100A9 está aumentada na pele lesionada de pacientes com psoríase vulgar, e esse aumento está correlacionado positivamente com outros parêmetros inflamatórios envolvidos com o desenvolvimento e manutenção da doença. Além disso, observamos que a expressão de S100A9 também está aumentada na pele, bem como nos linfonodos drenantes da pele de camundongos com psoríase induzida por imiquimode. Demonstramos que a proteína S100A9 está envolvida com a hiperproliferação dos queratinócitos, inflamação da derme e epiderme e a neovascularização da pele. Nossos dados mostram ainda que S100A9 pode ativar células dendríticas, induzindo a produção de IL-6 via TLR4 e aumenta a expressão gênica de $I l 23$ na pele, o que provavelmente está influenciando o aumento da frequência de linfócitos TCR $\gamma \delta$ produtores de IL-17. Além disso, nossos dados demonstram que S100A9 produzida pelos queratinócitos é mais importante para a hiperproliferação dos queratinócitos, comparado com as células mielóides produtoras de S100A9. Todos esses dados agregam mais um papel para S100A9 e avançam no conhecimento dessa molécula no desenvolvimento da psoríase.

Alguns trabalhos mostraram que S100A9 está associada com várias doenças inflamatórias, como vasculite (RASTALDI, 2000), artrite reumatoide (FROSCH, 2007), artrite psoriásica 
(KANE, 2003) e psoríase (BENOIT, 2006). Porém, poucos trabalhos tem explorado o papel dessa proteína nessas doenças inflamatórias. O aumento de S100A9 já havia sido observado na pele e no soro de pacientes com psoríase (CHIMENTI, 2016; WILSMANN-THEIS, 2016). Wilsmann-Theis e colaboradores mostraram que além de S100A9, outras proteínas da família S100A, como S100A7 e S100A12 estão aumentadas no soro de pacientes com psoríase (WILSMANN-THEIS, 2016).

Nossas análises de bioinformática de amostras de pele lesionada de pacientes com psoríase confirmaram esses achados da literatura. Esse aumento de S100A9 já foi sugerido como possível biomarcador da doença e parece estar associado com o agravamento da psoríase (WILSMANN-THEIS, 2016; BENOIT, 2006; HANSSON, 2014). Um dos nossos objetivos futuros é avaliar se diferentes tratamentos farmacológicos alteram os níveis sistêmicos de S100A9 em pacientes com psoríase. Para isso, estamos organizando um banco de amostras de pacientes atendidos pelo Hospital das Clínicas de Ribeirão Preto. Estamos coletando e armazenando o soro, células mononucleares do sangue periférico (PBMCs) e granulócitos de pacientes com psoríase e artrite psoriásica para futuras análises.

Nossos achados confirmaram o aumento de S100A9 na pele pacientes, mas pra entender o papel dessa molécula no desenvolvimento da doença, utilizamos o modelo experimental de psoríase induzido por imiquimode. O IMQ é um medicamento usado para o tratamento de alguns tipos de carcinoma basocelular superficial, verrugas presentes na região genital, entre outras aplicações. Seu mecanismo de ação ainda não é completamente descrito, mas alguns trabalhos relatam que a aplicação tópica desse produto induz ativação de células dendríticas dermais, via TLR7, com consequente produção de interferon. O modelo de psoríase induzido por IMQ começou a ser usado depois que alguns pacientes, após aplicação tópica de IMQ, relataram uma reação inflamatória cutânea da pele, com eritema e descamação, sinais clássicos da psoríase (WU, 2004; GILLIET, 2004). VAN DER FITS e colaboradores (2009) foram um 
dos primeiros grupos a utilizar o IMQ para simular modelo de psoríase em camundongos. A inflamação produzida na pele pelo IMQ se dá graças ao infiltrado inflamatório que inclui células dendríticas e linfócitos, que são células com papéis bem estabelecidos no desenvolvimento e manutenção da psoríase. Estudos mostraram que a via de IL-23/IL-17 apresenta um papel importante no desenvolvimento da psoríase (DI CESARE, 2009; WEAVER, 2007; BETTELLI, 2007; KASTELEIN, 2007). Esta via também participa da inflamação da pele no modelo de IMQ (HA, 2014; YOSHIKI, 2014). Animais que tiveram os receptores para IL-17 e IL-23 bloqueados apresentaram uma diminuição significante nos sinais de inflamação após aplicação de IMQ (VAN DER FITS, 2009). Apesar de apresentar várias limitações, esse é um dos modelos mais bem caracterizado e utilizado na literatura. Uma das maiores limitações seria entender o papel da imunidade adaptativa nesse modelo, visto que após 6 dias de aplicação de IMQ os sinais da inflamação começam a regredir (VAN DER FITS, 2009). Além disso, alguns trabalhos mostraram que a maior parte da produção de IL-17 responsável pelos sinais inflamatórios vistos no modelo são de origem de linfócitos TCR $\gamma \delta$ (CAI, 2011; PANTELYUSHIN, 2012).

GUTTMAN-YASSKY e colaboradores (2008) demonstraram que existe uma expressão diferencial de genes entre a pele lesionada e não lesionada de pacientes com psoríase e pacientes com dermatite atópica. S100A9, S100A8, IL-123, IL-17 E LCN2 entre ouros genes estavam diferencialmente expressos e aumentados na pele lesionada de pacientes com psoríase em comparação com outros grupos (GUTTMAN-YASSKY, 2008). O nosso trabalho foi o primeiro a fazer uma caracterização da expressão de S100A9 no modelo de psoríase experimental por IMQ. Mostramos por diferentes métodos que a expressão de S100A9 está aumentada tanto na pele quanto nos linfonodos de camundongos nesse modelo. Mostramos que outros genes já descritos como importantes para a proliferação de queratinócitos e outros genes que 
sabidamente contribuem para o desenvolvimento da psoríase estão aumentados como S100a8, K17, Il23, Il22, Il17, Il6 e Ill .

LCN2 já foi encontrada aumentada no soro e na pele lesionada de pacientes com psoríase. A maioria desses alvos já foram descritos como importantes no desenvolvimento da psoríase. LCN2 contribui para a fisiopatologia da psoríase, por modular a quimiotaxia e liberação de citocinas pelos neutrófilos (SHAO, 2016). A proteína K17 é um marcador clássico de ativação e proliferação de queratinócitos e está associada com o desenvolvimento da psoríase (LEIGH, 1995). O eixo IL-23/IL-17/IL-22 tem um papel central no desenvolvimento e manutenção da psoríase (LOWES, 2013). S1008 já foi encontrada aumentada no soro e na pele de pacientes com psoríase, embora não tenham muitos estudos explicando o papel desse na doença (Benoit, 2006). Níveis séricos aumentados de IL-6, IL1- $\beta$, TNF- $\alpha$, IL-8, IL-12, IL-18 estão correlacionados com maior atividade e severidade da psoríase (ARICAN, 2005). Através de análise de bioinformática observamos que o aumento da expressão de S100A9 está correlacionada positivamente com $K R T 17, L C N 2$, $I L-22, I L-36 g$ e $I L-23$. O correlação positiva entre S100A9 e esses outros genes sugere uma possível participação dessa molécula no desenvolvimento da psoríase.

S100A9 tem sido caracterizada como um componente importante da imunidade inata e está expressa em células mielóides como os neutrófilos, células dendríticas, monócitos e macrófagos em estágios iniciais de diferenciação (LAGASSE, 1988; ODINK, 1987). Corroborando isso, nossos dados de imunofluorescência mostraram que a expressão de S100A9 também está aumentada nos linfonodos, e que esse aumento está co-localizado com células dendríticas CD11c. No entanto, outras técnicas e experimentos precisam ser realizados para confirmar que as células dendríticas poderiam estar produzindo S100A9 após aplicação de IMQ. Para isso, isolaremos macrófagos e células dendríticas da pele e do linfonodo por citometria de fluxo e monócitos e neutrófilos do sangue por gradientes de percoll e avaliaremos 
a expressão de S100a9 por qPCR. Demonstramos também que o aumento de S100A9 nos linfonodos drenantes pode ser visto a partir do $1^{\circ}$ dia após aplicação de IMQ, enquanto que na pele a proteína aumenta a partir do $3^{\circ}$. O IMQ atua principalmente em TLR7 presente em células dendríticas (LOWES, 2014). Nossa hipótese é que depois de serem ativadas, as células dendríticas dermais poderiam migrar para os linfonodos drenantes, produzindo S100A9 antes que os queratinócitos da epiderme. Para provar isso, utilizaremos células dendríticas dermais de camundongos GFP.

A psoríase é uma doença que apresenta sinais clássicos, como eritema, descamação, e espessamento da pele (ARRUDA, 2001). Esses sinais são resultado da hiperproliferação de queratinócitos, mediado por células do sistema imune, como células dendríticas e linfócitos T (SCHON, M. P. 2005; SABAT, R. 2007). Os queratinócitos cumprem um papel central na manutenção da doença. Uma vez ativados, estes liberam mediadores inflamatórios que acentuam e amplificam os sinais inflamatórios da psoríase. A liberação de TNF, IL1- $\beta$, IL-6, que ativa células dendríticas dermais. Além disso, essas células produzem IL-8 que recruta neutrófilos, e também produzem TGF- $\beta$, que é essencial para a formação de neovasos. Todos esses eventos contribuem para a manutenção do processo inflamatório observado na psoríase. (NESTLE, 2009; SANKAR, 2017; WILLEMS-WIDYASTUTI, 2011).

Nossos dados mostram que S100A9 é uma proteína crítica para o espessamento da pele, pois na deficiência genética total, houve uma redução do eritema, espessura da pele e acantose, acompanhado de menor formação de neovasos e diminuição do peso do baço. Corroborando nossos dados, SCHONTHALER e colaboradores mostraram que o complexo S100A8-S100A9, também conhecido por calprotectina é crítico para o espessamento da pele, após aplicação tópica de IMQ e esse mecanismo é mediado. Nesse mesmo trabalho observou-se que a ausência genética de S100A9 comprometeu os níveis de C3, uma proteína do complemento, que tem um papel importante na inflamação da pele. E essa relação de S100A9/C3 foi o que explicou a 
relevância de S100A9 no desenvolvimento da psoríase. No entanto, esse trabalho não explorou o papel de S100A9 nas células do sistema imune, que foi um dos objetivos do nosso trabalho. O nosso trabalho soma com os dados já encontrados, mas apresenta um novo papel para S100A9 na imunopatogênese da psoríase.

BJORK e colabores (2009) sugeriram S00A9 como alvo no tratamento de doenças autoimunes. Estes demostraram que o paquinimode, uma composto que se liga em S100A9 e impede que ela atue nos seus receptores. Essa droga começou a ser testada em vários modelos experimentais e se mostrou eficiente na prevenção e diminuição de lesões causadas em modelo de osteoartite (SCHELBERGEN, 2015). No entanto, essa ferramenta farmacológica nunca tinha sido usada para prevenir ou tratar a psoríase em modelo experimental. Nossos dados mostraram que o tratamento com o PAQ também diminuiu o eritema, espessamento da pele e acantose, acompanhado de menor formação de neovasos e diminuição do peso do baço.

Sabendo que a ausência ou inibição de S100A9 diminuiu o espessamento da epiderme e outros parâmetros inflamatórios nós hipotetizamos que S100A9 poderia influenciar na frequência de células Th17 e TCR $\gamma \delta$ produtoras de IL-17. De fato, a ausência ou inibição de S100A9 reduziu substancialmente a frequência de linfócitos TCR $\gamma \delta$ produtores de IL-17 nos linfonodos drenantes da pele, mas não alterou a frequência de células T CD4 produtoras de IL17. Isso sugere um possível papel entre S100A9 e os linfócitos TCR $\gamma \delta$ IL-17+. CAI e PANTELYUSHIN mostraram que a maior fonte de IL-17 responsável pelos sinais inflamatórios vistos no modelo de psoríase por IMQ são de origem de linfócitos TCR $\gamma \delta$. Isso pode explicar porque mesmo sem alterar os níveis de linfócitos TCD4 IL17+, a ausência ou inibição de S100A9 diminuiu os parâmetros inflamatórios na pele (CAI, 2011; PANTELYUSHIN, 2012).

Além das células envolvidas no agravamento da psoríase, outras células responsáveis pela regulação da resposta inflamatória, como os linfócitos T reguladores, que cumprem um papel 
central na tolerância periférica evitando o desenvolvimento de respostas inflamatórias exacerbadas e desenvolvimento de doenças autoimunes. Desta forma, investigamos se S100A9 poderia influenciar na frequência dessas células e observamos que a ausência ou inibição de S100A9 não alterou a frequência de linfócitos TCD4FOxP3+.

Sabendo que S100A9 estava modulando somente a frequência de células TCR $\gamma \delta$ IL-17+, nós hipotetizamos que S100A9 poderia modular a ativação de células dendríticas, e, consequentemente, a produção de IL-23. CAI e colaboradores (2011) mostraram que IL-23, predominantemente, estimula linfócitos $\mathrm{TCR} \gamma \delta$ a produzir IL-17, o que leva a uma maior progressão da inflamação na pele. Além disso, os linfócitos TCR $\gamma \delta 17+$ apresentam um papel importante no controle de infecções e em doenças inflamatórias crônicas como a psoríase (PAPOTTO, 2017; CAI, 2011). De fato, nossos dados mostram que a ausência ou inibição de S100A9 diminui a expressão de Il23 na pele, sugerindo que S100A9 esteja modulando a ativação de células dendríticas. Corroborando nossos dados, RIOL-BLANCO e colaboradores (2014) mostraram que a ausência de neurônios sensoriais na pele diminui a produção de IL-23 por células dendríticas dermais, diminuindo a espessura da pele, pela diminuição de IL-17, resultado da diminuição da frequência de linfócitos TCR $\gamma \delta$. Este mesmo grupo mostrou que a ausência do receptor de IL-23 compromete o desenvolvimento da psoríase. A IL-23, uma citocina crítica no início dessa resposta inflamatória que culmina na inflamação crônica da psoríase já é alvo de tratamento em humanos (LEONARDI, 2008).

A fim de demonstrar se S100A9 estaria realmente modulando uma maior produção de citocinas pró-inflamatórias em células dendríticas, avaliamos o papel dessa molécula in vitro. Nossos dados até agora mostram que S100A9 foi capaz de induzir a produção de IL-6, sozinha ou combinada com IMQ de forma dependente de TLR4. No mesmo sobrenadante, não conseguimos detectar IL-23, o qual era o alvo principal da nossa pergunta. Talvez tenhamos que modificar o tempo ou a densidade de células na cultura, mas isso é um dos próximos 
objetivos do estudo. Além disso, avaliaremos se a frequência de células produtoras de IL-23 na pele está reduzida na ausência ou inibindo S100A9.

Uma das perguntas que norteou boa parte da nossa pesquisa foi tentar entender qual grupo de células produtoras de S100A9 seriam as mais importantes para o desenvolvimento da psoríase em nosso modelo. Sabemos que tanto as células epiteliais quanto as células mielóides produzem S100A9 e são células já sabidamente importantes para o desenvolvimento da psoríase. Porém, até então, não estava claro quais dessas células produtoras de S100A9 seriam as mais importantes.

Uma das células mais bem caracterizadas no modelo de psoríase experimental são as células dendríticas, comprovadamente importantes para o início dos sinais inflamatórios observados no modelo (WOHN, 2013; SINGH, 2016). Porém, a participação dos neutrófilos e macrófagos nesse modelo ainda é controversa em muitos trabalhos. SUMIDA e colaboradores (2014) mostraram que a depleção de neutrófilos com anti-LY6G diminui os sinais inflamatórios, bem como espessamento da pele. No entanto, mais recentemente, COSTA e colaboradores (2017) mostraram que a sinalização deficiente de MYD88 em monócitos e macrófagos, mas não em neutrófilos, diminuiu os parâmetros inflamatórios da pele com diminuição da frequência de linfócitos $\gamma \delta$, via diminuição da produção de IL1- $\beta$ e IL-23 (SUMIDA, 2014; COSTA, 2017), sugerindo que os neutrófilos não teriam um papel tão importante no desenvolvimento da doença. Costa e colaboradores (2017) recentemente publicaram um trabalho mostrando que as células mielóides tem um papel importante no desenvolvimento da psoríase experimental, principalmente na fase tardia. Camundongos que tinham células hematopoiéticas deficientes para MyD88, apresentaram menor espessura da pele, além de diminuição do número de células CD45 em geral. O mesmo fenótipo foi visto em camundongos deficientes totais para MyD88, sugerindo que a via de MyD88 é dispensável em células não hematopoiéticas no modelo de psoríase por IMQ (COSTA, 2017). 
Embora muitos trabalhos tenham focado na importância de S100A9 nas células mielóides, alguns trabalhos tem tentado entender o papel desse mediador em células epiteliais. Animais deficientes para S100A9 tiveram uma redução do desenvolvimento da aterosclerose, com redução do acúmulo de macrófagos nas artérias (CROCE, 2009). Por conta da abundância de S100A9 nas células mielóides comparado com células não mieolóides acreditava-se que as células mielóides produtoras de S100A9 seriam mais importantes em diversas condições inflamatórias (AVERILL, 2011). Para testar essa hipótese, foi feita uma transferência de células mielóides de animais WT ou deficientes para S100A9-/- para animais que desenvolveriam aterosclerose após dieta específica. No entanto, os animais que receberam medula S100A9 -/não apresentaram redução da aterosclerose, ou diminuição nas lesões e acúmulo de macrófagos e neutrófilos nas artérias em relação ao grupo que recebeu medula WT. Isto sugere que as células não mielóides produtoras de S100A9 é que cumprem uma maior participação na fisiopatologia, nesse modelo de aterosclerose (AVERILL, 2011).

Para avaliar quais células produtoras de S100A9 seriam mais importantes geramos camundongos quimera, onde no produto final tínhamos camundongos deficientes para S100A9 nas células hematopoiéticas ou não hematopoiéticas. Nossos dados mostram que ambas as células produtoras de S100A9 parecem ser importantes para o espessamento da pele de acordo com a aplicação tópica de IMQ e para a frequência de linfócitos TCR $\gamma \delta$. No entanto, quando avaliamos os parâmetros histológicos fica claro que S100A9 presente nas células não hematopoéticas é mais importante para o aumento da espessura epiderme.

A psoríase, assim como outras doenças autoimunes, que não tem cura e apresenta tratamentos que diminuem os impactos da doença, prolongando o tempo entre recidivas, melhorando a qualidade de vida dos pacientes (RODRIGUES E TEIXEIRA, 2009). Porém, mais estudos são necessários para entender os mecanismos que envolvem o desenvolvimento da doença. Nós mostramos que a proteína S100A9 é importante para a expressão de I $l 23$, 
produção de IL-6 via TLR4 frequência linfócitos TCR $\gamma \delta$ produtores de IL-17. Nosso estudo avançou no conhecimento do papel de S100A9 no desenvolvimento e imunopatogênese da psoríase e a torna um alvo para futuras estratégias farmacológicas. 
CONCLUSÃO 


\section{CONCLUSÃO}

Nosso estudo demonstrou que S100A9 participa ativamente do desenvolvimento da psoríase, contribuindo para os sinais clássicos da doença como eritema, formação de neovasos e espessamento da pele. Adicionalmente, estamos propondo uma nova função para S100A9 na progressão dessa doença. Demonstramos que as células não hematopoiéticas produtoras de S100A9 tem uma maior participação no desenvolvimento da psoríase experimental. Além disso, demonstramos que S100A9 atua em células dendríticas induzindo a produção de IL-6 de maneira dependente de TLR4. Por fim, demosntramos que S100A9 aumenta a expressão de Il23 na pele e induz o aumento de linfócitos TCR $\gamma \delta$ produtores de IL-17. 
REFERÊNCIAS 


\section{REFERÊNCIAS}

1. Almeida I.M.M, Dissertação de Mestrado Integrado em Medicina: Psoríase e Fatores de Risco Cardiovascular. Instituto de Ciências Biomédicas de Abel Salazar da Universidade do Porto. 2011.

2. Arican, Ozer, et al. "Serum levels of TNF- $\alpha$, IFN- $\gamma$, IL-6, IL-8, IL-12, IL-17, and IL-18 in patients with active psoriasis and correlation with disease severity." Mediators of inflammation 2005.5 (2005): 273-279.

3. Arruda, Lúcia Helena Fávaro, Gladys AM Campbell, and Maria Denise F. Takahashi. "Psoríase." An. bras. dermatol 76.2 (2001): 141-167.

4. Averill, Michelle M., et al. "S100A9 differentially modifies phenotypic states of neutrophils, macrophages, and dendritic cells." Circulation (2011): CIRCULATIONAHA-110.

5. Benoit, S., et al. "Elevated serum levels of calcium-binding S100 proteins A8 and A9 reflect disease activity and abnormal differentiation of keratinocytes in psoriasis." British Journal of Dermatology 155.1 (2006): 62-66.

6. Berth-Jones, J. Psoriasis. Medicines. 2005; 33 (1), pp. 50-56.

7. Bettelli, Estelle, Mohamed Oukka, and Vijay K. Kuchroo. "TH-17 cells in the circle of immunity and autoimmunity." Nature immunology 8.4 (2007): 345-350.

8. Björk, Per, et al. "Identification of human S100A9 as a novel target for treatment of autoimmune disease via binding to quinoline-3-carboxamides." PLoS biology 7.4 (2009): e1000097.

9. Bruner, Christine R., et al. "A systematic review of adverse effects associated with topical treatments for psoriasis." Dermatology online journal 9.1 (2003).

10. Cai, Yihua, et al. "Pivotal role of dermal IL-17-producing $\gamma \delta \mathrm{T}$ cells in skin inflammation." Immunity 35.4 (2011): 596-610.

11. Campalani E, Barker JN. The clinical genetics of psoriasis. Current Genomics. 2005; 6: 51-60.

12. Carneiro S.C.S., Tese Psoríase: mecanismos de doença e implicações terapêuticas. 2007. Faculdade de Medicina da Universidade de São Paulo.

13. Chimenti, Maria Sole, et al. "S100A8/A9 in psoriatic plaques from patients with psoriatic arthritis." Journal of International Medical Research 44.1_suppl (2016): 33-37.

14. Chuong, C.M., Nickoloff, B.J., Elias, P.M., Goldsmith, L.A., Macher, E., Maderson, P.A., Sundberg, J.P., Tagami, H., Plonka, P.M., Thestrup- Pederson, K., Bernard, B.A., Schroder, J.M., Dotto, P., Chang, C.M., Williams, M.L., Feingold, K.R., King, L.E., Kligman, A.M., Rees, J.L., Christophers, E. What is the 'true' function of skin? Exp. Dermatol., 11: 159- 187, 2002.

15. Coimbra, S., et al. "Interleukin (IL)-22, IL-17, IL-23, IL-8, vascular endothelial growth factor and tumour necrosis factor- $\alpha$ levels in patients with psoriasis before, during and after psoralenultraviolet A and narrowband ultraviolet B therapy." British Journal of Dermatology 163.6 (2010): 1282-1290.

16. Costa, Sara, et al. "Role of MyD88 signaling in the imiquimod-induced mouse model of psoriasis: focus on innate myeloid cells." Journal of Leukocyte Biology (2017): jlb-3MA0217.

17. Da Silva A.C.A., Lambert A.P.F., Anticorpos Monoclonais na Terapêutica da Psoríase, Revista Electrónica de Farmácia, 2011. 3(4):41-58.

18. de Psoríase, SBD Consenso Brasileiro. "Guias de avaliação e tratamento Sociedade Brasileira de Dermatologia." Rio de Janeiro: Sociedade Brasileira de Dermatologia (SBD) (2012).

19. De Pianto, Daryle, et al. "Keratin 17 promotes epithelial proliferation and tumor growth by polarizing the immune response in skin." Nature genetics 42.10 (2010): 910-914. 
20. Di Cesare, Antonella, Paola Di Meglio, and Frank O. Nestle. "The IL-23/Th17 axis in the immunopathogenesis of psoriasis." Journal of Investigative Dermatology 129.6 (2009): 13391350.

21. Diluvio L, Chimenti S. Overview of psoriasis. In: Chimenti S. Psoriasis. 1st ed. Florence, Italy: S.E.E. Società Editrice Europea di Nicodemo Maggiulli \& C. snc; 2005. p. 19-24.

22. Duarte, Artur Antonio, and Flavia Barbour Chehin. "Psoríase moderada a grave tratada com infliximabe em 53 pacientes: perfil dos pacientes, eficácia e efeitos adversos." An Bras Dermatol (2011): 257-263.

23. Duffin KC, Chandran V, Gladman DD, Krueger GG, Elder JT, Rahman P. Genetics of psoriasis and psoriatic arthritis: update and future direction. J Rheumatol. 2008; 35(7):1449-53.

24. Eckert, Richard L., et al. "S100 proteins in the epidermis." Journal of Investigative Dermatology 123.1 (2004): 23-33.

25. Edgeworth, Jonathan, et al. "Identification of p8, 14 as a highly abundant heterodimeric calcium binding protein complex of myeloid cells." Journal of Biological Chemistry 266.12 (1991): 7706-7713.

26. Ehrchen, Jan M., et al. "The endogenous Toll-like receptor 4 agonist S100A8/S100A9 (calprotectin) as innate amplifier of infection, autoimmunity, and cancer." Journal of leukocyte biology 86.3 (2009): 557-566.

27. Elder, James T., et al. "The genetics of psoriasis 2001: the odyssey continues." Archives of dermatology 137.11 (2001): 1447-1454.

28. Elkayam O, Ophir J, Yaron M, Caspi D. Psoriatic arthritis: interrelantionships between skin and joint manifestations related to onset, course and distribution. Clin Rheumatol 2000; 19: 301-305.

29. Frosch, M., and J. Roth. "New insights in systemic juvenile idiopathic arthritis-from pathophysiology to treatment." Rheumatology 47.2 (2007): 121-125.

30. Ganz, Tomas. "Defensins: antimicrobial peptides of innate immunity." Nature Reviews Immunology 3.9 (2003): 710-720.

31. Gautier, Laurent, et al. "affy-analysis of Affymetrix GeneChip data at the probe level." Bioinformatics 20.3 (2004): 307-315.

32. Gilliet, Michel, et al. "Psoriasis triggered by toll-like receptor 7 agonist imiquimod in the presence of dermal plasmacytoid dendritic cell precursors." Archives of dermatology 140.12 (2004): 1490-1495.

33. Greb, J. E., Goldminz, A. M., Elder, J. T., Lebwohl, M. G., Gladman, D. D., Wu, J. J., ... Gottlieb, A. B. Psoriasis. Nature Reviews Disease Primers. (2016) 2, [16082].

34. Grimbaldeston, Michele A., et al. "S100A8 induction in keratinocytes by ultraviolet A irradiation is dependent on reactive oxygen intermediates." Journal of Investigative Dermatology 121.5 (2003): 1168-1174.

35. Guttman-Yassky, E., Nograles, K., Krueguer, J. (2011). Contrasting pathogenesis of atopic dermatitis and psoriasis - Part I: clinical and pathologic concepts. Journal of Allergy and Clinical Immunology, 127, pp. 1110-1118;

36. Guttman-Yassky, Emma, et al. "Low expression of the IL-23/Th17 pathway in atopic dermatitis compared to psoriasis." The Journal of Immunology 181.10 (2008): 7420-7427.

37. Ha, Hye-Lin, et al. "IL-17 drives psoriatic inflammation via distinct, target cell-specific mechanisms." Proceedings of the National Academy of Sciences111.33 (2014): E3422-E3431.

38. Hägg D, Eriksson M, Sundström A, Schmitt-Egenolf M. The higher proportion of men with psoriasis treated with biologics may be explained by more severe disease in men. PLoS One. 2013; 8: e63619.

39. Hancock, Robert EW, and Hans-Georg Sahl. "Antimicrobial and host-defense peptides as new anti-infective therapeutic strategies." Nature biotechnology 24.12 (2006): 1551-1557. 
40. Hansson, Claes, Catharina Eriksson, and Gerd-Marie Alenius. "S-calprotectin (S100A8/S100A9): a potential marker of inflammation in patients with psoriatic arthritis." Journal of immunology research 2014 (2014).

41. Hessian, Paul A., Jonathan Edgeworth, and Nancy Hogg. "MRP-8 and MRP-14, two abundant $\mathrm{Ca}(2+)$-binding proteins of neutrophils and monocytes." Journal of leukocyte biology 53.2 (1993): 197-204.

42. Kaçar, Cahit, et al. "Sacroiliac joint involvement in psoriasis." Rheumatology international 30.9 (2010): 1263-1266.

43. Källberg, Eva, et al. "S100A9 interaction with TLR4 promotes tumor growth." PloS one 7.3 (2012): e34207.

44. Kane, David, et al. "Increased perivascular synovial membrane expression of myeloid-related proteins in psoriatic arthritis." Arthritis \& Rheumatology 48.6 (2003): 1676-1685.

45. Kastelein, Robert A., Christopher A. Hunter, and Daniel J. Cua. "Discovery and biology of IL23 and IL-27: related but functionally distinct regulators of inflammation." Annu. Rev. Immunol. 25 (2007): 221-242.

46. Katz, H. Irving, Jill Waalen, and Eileen Enny Leach. "Acitretin in psoriasis: an overview of adverse Cruz Lopes, Luciane, et al. "Medicamentos biológicos para o tratamento de psoríase em sistema público de saúde." Revista de Saúde Pública 48.4 (2014).

47. Koster, M.I., Roop, D.R. Genetic pathways required for epidermal morphogenesis. Eur. J. Cell Biol., 83: 625-629, 2004.

48. Krueger, G., Ellis, C. Psoriasis - recent advances in understanding its pathogenesis and treatment. Journal of American Academy of Dermatology. 2005. 53, pp. 94-100.

49. Krueger, J. G., and A. Bowcock. "Psoriasis pathophysiology: current concepts of pathogenesis." Annals of the rheumatic diseases 64.suppl 2 (2005): ii30-ii36.

50. Krueger, J.G., Bowcock, A. Psoriasis pathophysiology: current concepts of pathogenesis. Ann. Rheum. Dis., 64: 30-36, 2005.

51. Lagasse, Eric, and ROGER G. Clerc. "Cloning and expression of two human genes encoding calcium-binding proteins that are regulated during myeloid differentiation." Molecular and cellular biology 8.6 (1988): 2402-2410.

52. Leek, Jeffrey T., and John D. Storey. "A general framework for multiple testing dependence." Proceedings of the National Academy of Sciences 105.48 (2008): 18718-18723.

53. Leek, Jeffrey T., and John D. Storey. "Capturing heterogeneity in gene expression studies by surrogate variable analysis." PLoS genetics 3.9 (2007): e161.

54. Leigh, I. M., et al. "Keratins (K16 and K17) as markers of keratinocyte hyperproliferation in psoriasis in vivo and in vitro." British Journal of Dermatology 133.4 (1995): 501-511.

55. Leonardi, Craig L., et al. "Efficacy and safety of ustekinumab, a human interleukin-12/23 monoclonal antibody, in patients with psoriasis: 76-week results from a randomised, doubleblind, placebo-controlled trial (PHOENIX 1)." The Lancet 371.9625 (2008): 1665-1674.

56. Lowes, Michelle A., et al. "The IL-23/T17 pathogenic axis in psoriasis is amplified by keratinocyte responses." Trends in immunology 34.4 (2013): 174-181.

57. Lowes, Michelle A., Mayte Suárez-Fariñas, and James G. Krueger. "Immunology of psoriasis." Annual review of immunology 32 (2014): 227-255.

58. Markowitz, Joseph, and William E. Carson. "Review of S100A9 biology and its role in cancer." Biochimica et Biophysica Acta (BBA)-Reviews on Cancer 1835.1 (2013): 100-109.

59. Nestle, Frank O., et al. "Skin immune sentinels in health and disease." Nature reviews. Immunology 9.10 (2009): 679.

60. Nijsten, Tamar, and Marlies Wakkee. "Complexity of the association between psoriasis and comorbidities." Journal of Investigative Dermatology 129.7 (2009): 1601-1603.

61. Nukui, Takamasa, et al. "S100A8/A9, a key mediator for positive feedback growth stimulation of normal human keratinocytes." Journal of cellular biochemistry 104.2 (2008): 453-464. 
62. Odink, Karel, et al. "Two calcium-binding proteins in infiltrate macrophages of rheumatoid arthritis." Nature 330.6143 (1987): 80-82.

63. Ortonne JP. Aetiology and pathogenesis of psoriasis. Br J Dermatol. 1996; 135(Suppl 49):1-5.

64. Pantelyushin, Stanislav, et al. "Ror $\gamma t+$ innate lymphocytes and $\gamma \delta$ T cells initiate psoriasiform plaque formation in mice." The Journal of clinical investigation 122.6 (2012): 2252.

65. Papotto, Pedro H., Julie C. Ribot, and Bruno Silva-Santos. "IL-17+[gamma][delta] T cells as kick-starters of inflammation." Nature Immunology 18.6 (2017): 604-611.

66. Proksch, Ehrhardt, Johanna M. Brandner, and Jens-Michael Jensen. "The skin: an indispensable barrier." Experimental dermatology 17.12 (2008): 1063-1072.

67. Rammes, Anke, et al. "Myeloid-related protein (MRP) 8 and MRP14, calcium-binding proteins of the S100 family, are secreted by activated monocytes via a novel, tubulin-dependent pathway." Journal of Biological Chemistry 272.14 (1997): 9496-9502.

68. Rastaldi, Maria Pia, et al. "Glomerular monocyte-macrophage features in ANCA-positive renal vasculitis and cryoglobulinemic nephritis." Journal of the American Society of Nephrology 11.11 (2000): 2036-2043.

69. Riol-Blanco, Lorena, et al. "Nociceptive Sensory Neurons Drive Interleukin-23 Mediated Psoriasiform Skin Inflammation." Nature 510.7503 (2014): 157.

70. Rodrigues, A., Teixeira, R. Desvendando a psoríase. RBAC. 2009. 41 (4), pp. 303-309;

71. Ruiz, Danilo Garcia, Mário Newton Leitão de Azevedo, and Omar Lupi da Rosa Santos. "Psoriatic arthritis: a clinical entity distinct from psoriasis?." Revista brasileira de reumatologia 52.4 (2012): 630-638.

72. Ryan, T. The ageing of the blood supply and the lymphatic drainage of the skin. Micron., 35: 161-171, 2004.

73. Sabat R, Philipp S, Höflich C, Kreutzer S, Wallace E, Asadullah K, et al. Immunopathogenesis of psoriasis. Experimental Dermatology. 2007; 16(10): 779-798.

74. Sabat, Robert, and Kerstin Wolk. "Research in practice: IL-22 and IL-20: significance for epithelial homeostasis and psoriasis pathogenesis." JDDG: Journal der Deutschen Dermatologischen Gesellschaft 9.7 (2011): 518-523.

75. Sankar, Lakshna, et al. "Expression of Angiogenic Factors in Psoriasis Vulgaris." Journal of clinical and diagnostic research: JCDR 11.3 (2017): EC23.

76. Scaccabarozzi, Luciana, et al. "Análise de custo por resposta dos medicamentos biológicos no tratamento da psoríase moderada a grave sob as perspectivas dos sistemas de saúde público e privado, no Brasil." JBES: Brazilian Journal of Health Economics/Jornal Brasileiro de Economia da Saúde 8.2 (2016).

77. Schelbergen, R. F., et al. "Prophylactic treatment with S100A9 inhibitor paquinimod reduces pathology in experimental collagenase-induced osteoarthritis." Annals of the rheumatic diseases 74.12 (2015): 2254-2258.

78. Schiopu, Alexandru, and Ovidiu S. Cotoi. "S100A8 and S100A9: DAMPs at the crossroads between innate immunity, traditional risk factors, and cardiovascular disease." Mediators of inflammation 2013 (2013).

79. Schön MP, Henning-Boehncke W. Psoriasis. N Engl J Med. 2005; 352: 1899-1912.

80. Schonthaler, Helia B., et al. "S100A8-S100A9 protein complex mediates psoriasis by regulating the expression of complement factor C3." Immunity39.6 (2013): 1171-1181.

81. Sfikakis, P. P., et al. "Psoriasis induced by anti-tumor necrosis factor therapy: a paradoxical adverse reaction." Arthritis \& Rheumatology 52.8 (2005): 2513-2518. 
82. Shao, Shuai, et al. "Increased Lipocalin-2 contributes to the pathogenesis of psoriasis by modulating neutrophil chemotaxis and cytokine secretion." Journal of Investigative Dermatology 136.7 (2016): 1418-1428.

83. Singh, Tej Pratap, et al. "Monocyte-derived inflammatory Langerhans cells and dermal dendritic cells mediate psoriasis-like inflammation." Nature communications 7 (2016): 13581.

84. Sumida, Hayakazu, et al. "Interplay between CXCR2 and BLT1 facilitates neutrophil infiltration and resultant keratinocyte activation in a murine model of imiquimod-induced psoriasis." The Journal of Immunology 192.9 (2014): 4361-4369.

85. Tong, Louis, et al. "S100A proteins as molecular targets in the ocular surface inflammatory diseases." The ocular surface 12.1 (2014): 23-31.

86. Valdimarsson, Helgi. "The genetic basis of psoriasis." Clinics in dermatology 25.6 (2007): 563567.

87. Van der Fits, Leslie, et al. "Imiquimod-induced psoriasis-like skin inflammation in mice is mediated via the IL-23/IL-17 axis." The Journal of Immunology182.9 (2009): 5836-5845.

88. Weaver, Casey T., et al. "IL-17 family cytokines and the expanding diversity of effector T cell lineages." Annu. Rev. Immunol. 25 (2007): 821-852.

89. Welss, T., Basketter, D.A., Schroder, K.R. In vitro skin irritation: facts and future. State of the art review of mechanisms and models. Toxicol. In Vitro, 18: 231- 243, 2004.

90. Willems-Widyastuti, Anna, et al. "Transforming growth factor-1 induces angiogenesis in vitro via VEGF production in human airway smooth muscle cells." (2011).

91. Williams, I.R., Kupper, T.S. Immunity at the surface: homeostatic mechanisms of the skin immune system. Life Sci., 58: 1485-1507, 1996.

92. Wilsmann-Theis, D., et al. "Among the S100 proteins, S100A12 is the most significant marker for psoriasis disease activity." Journal of the European Academy of Dermatology and Venereology 30.7 (2016): 1165-1170.

93. Wolk, Kerstin, et al. "IL-22 regulates the expression of genes responsible for antimicrobial defense, cellular differentiation, and mobility in keratinocytes: a potential role in psoriasis." European journal of immunology 36.5 (2006): 1309-1323.

94. Wu, Jason K., Greg Siller, and Geoff Strutton. "Psoriasis induced by topical imiquimod." Australasian journal of dermatology 45.1 (2004): 47-50.

95. Yoshiki, Ryutaro, et al. "IL-23 from Langerhans cells is required for the development of imiquimod-induced psoriasis-like dermatitis by induction of IL-17A-producing $\gamma \delta \mathrm{T}$ cells." Journal of Investigative Dermatology 134.7 (2014): 1912-1921.

96. Zenz, Rainer, et al. "Psoriasis-like skin disease and arthritis caused by inducible epidermal deletion of Jun proteins." Nature 437.7057 (2005): 369-375.

97. Zimmer, Danna B., et al. "The S100 protein family: history, function, and expression." Brain research bulletin 37.4 (1995): 417-429. 